\title{
Experiments in Optimal Spatial Segmentation of Local Regions using Categorical and Quantitative Data
}

\author{
Kurt K. Benke and Lyndon R. Benke
}

\begin{abstract}
A computational framework is described for optimal spatial allocation of land use categories across a geographical region. The relevance of optimisation, its advantages and disadvantages, and details on mathematical background relevant to natural resource management are discussed. Experiments were conducted with a probabilistic optimisation procedure using a prototype software package, with numerical results and visualisation provided for a case study. Results are provided for land use optimisation with an indication of the possible improvement in regional revenue, given data on crop yields and market prices for various commodities. When revenue is used as the performance index for optimisation, the approach reveals a significant improvement is possible when applied to a production region in Victoria, Australia. A conclusion drawn from the experiments is that the problem is quite complex in nature and open ended with many variables. An agenda is suggested for further development of the modelling strategy, by way of incremental improvements, as more environmental information is acquired and further constraint factors are considered.
\end{abstract}

Keywords spatial allocation, commodities, optimisation, revenue, segmentation, simulation, visualisation

\section{K. K. Benke}

Department of Infrastructure Engineering, University of Melbourne, Parkville, Victoria, 3010, Australia.

Department of Primary Industries - Parkville Centre, PO Box 4166, Parkville, Victoria, 3052, Australia.

Email: kurt.benke@dpi.vic.gov.au

\section{L.R. Benke}

Air Operations Division, Defence Science and Technology Organisation (DSTO), PO Box 4331, Melbourne Vic 3001, Australia. Email: 1yndon.benke@dsto.defence.gov.au 


\title{
Experiments in Optimal Spatial Segmentation of Local Regions using Categorical and Quantitative Data
}

\begin{abstract}
A computational framework is described for optimal spatial allocation of land use categories across a geographical region. The relevance of optimisation, its advantages and disadvantages, and details on mathematical background relevant to natural resource management are discussed. Experiments were conducted with a probabilistic optimisation procedure using a prototype software package, with numerical results and visualisation provided for a case study. Results are provided for land use optimisation with an indication of the possible improvement in regional revenue, given data on crop yields and market prices for various commodities. When revenue is used as the performance index for optimisation, the approach reveals a significant improvement is possible when applied to a production region in Victoria, Australia. A conclusion drawn from the experiments is that the problem is quite complex in nature and open ended with many variables. An agenda is suggested for further development of the modelling strategy, by way of incremental improvements, as more environmental information is acquired and further constraint factors are considered.
\end{abstract}

Keywords spatial allocation, commodities, optimisation, revenue, segmentation, simulation, visualisation 


\section{Background}

\subsection{Introduction}

Agricultural production is increasingly important in the modern globalised economy and is being driven by the increasing demand from China and other rapidly developing economies. This paper describes an experimental modelling framework for the spatial allocation of commodity production over a geographic region in south west Victoria, Australia. The paper develops the case for a discrete probabilistic simulation-based approach as a framework if one is to satisfy future options of optimisation, visualisation and uncertainty analysis. The paper also describes how a real-world multivariate optimisation approach could lead to a significant improvement given the scale of the problem domain (the agricultural sector accounts for a significant proportion of national GDP). Some issues and constraints on spatial allocation of commodity production are discussed.

\subsection{Resource Allocation}

Optimal allocation of resources, including regional location of agricultural production, has been the subject of considerable ongoing research (see, for example, Detlef and Jensen 2004; Herath and Prato 2006; Koomen et al. 2007). Computer simulation studies of land use allocation are popular because of economic implications and ecological effects, and are well suited to studies in natural resource management (Weintraub and Romero 2006; Koomen et al. 2007, 2008). Land use has a significant impact on the hydrological status of a local region, with significant effects observed with respect to groundwater recharge and evaporation rates (Bari and Smettem 2006). These issues have been investigated in a number of recent studies using a scenario-based model supplied with GIS-based data (Koomen 2007). The latter approach applies a logistic regression model to allocate a particular commodity to a cell in a regional map based on its land suitability.

The term 'land suitability' refers to the degree of match or fitness between commodity type and geographical location (see also Herath and Prato 2006). For example, one would not attempt to grow a water intensive crop such as rice in a desert region. Land suitability is associated with a specific combination of soil, climate and landscape characteristics and is assigned numerical values by a GISbased modelling process (Hossain et al. 2006; Pelizaro et al. 2010). Land suitability alone may not be a sufficient metric when a variety of crops are available for a defined region. Other factors, such as market price or production cost, will also affect the choice taken. The proportional allocation of crops to a region requires an assessment based on a figure of merit and can be expressed as an optimisation 
problem. An optimisation model may also include constraining environmental and economic factors, including transportation costs and market demand.

For very small scale problems in resource allocation and land-use optimisation, exhaustive search may be sufficient. Once the problem increases in size and complexity, however, an optimisation algorithm is required to solve the defined objective function within a reasonable time-frame and accuracy. An example of a deterministic approach to land-use allocation, showing the complexity involved, and incorporating uncertainty in the form of 'fuzziness', was described recently by Soliman et al. (2008). In another study, a land-use optimisation model based on a genetic algorithm for the decision-making process was proposed by Wyatt $(2006,2008)$ and Hossain et al. (2006). This explorative work was informative, but revealed some possible constraints on genetic algorithms for optimisation in land use optimisation. These constraints included uncertainty in parameter settings and the use of heuristic reinforcement rules which could affect reliability and speed of convergence.

Recent experiments have clarified the potential of a probabilistic-based methodology, with actual implementation using the original software platform used for the genetic algorithm used by Wyatt (2006), extending and modifying it appropriately, and including a different search strategy (Benke et al. 2011). The optimal allocation software tool used was converted into a multiple choice procedure offering a deterministic approach based on a genetic algorithm or an iterative probabilistic approach. This change provided a simulation-based solution option compatible with future risk assessment and statistical uncertainty analysis.

In the past, models in natural resource management, land use allocation and hydrology have involved the use of optimisation for calibration and output maximisation (see the review by Fischer et al. 2009). Linear programming is deterministic in nature, as are many traditional approaches such as Newton's method and gradient descent procedures (Hillier and Lieberman 2004; Said and Koomen et al. 2008; Wegman 2009). A second class of algorithms, motivated by natural applications where data is partial or approximate, can be described as meta-heuristic, and is distinguished by an iterative process where a fitness function is updated according to a trial-and-error process (Said and Wegman 2009). Such approaches include evolutionary algorithms, genetic algorithms, simulated annealing and Tabu search Fischer et al. 2009; Said and Wegman, 2009). Although not formally specified with proven convergence theorems, these approaches can often be very effective and more widely applicable than calculus-based methods.

Numerical methods of optimisation include Shuffle Complex Evolution or SCE (Duan et al. 1992), which uses multiple proto-genetic algorithms, Branch and Bound methods (Horst et al. 2000), and the Radial Basis Function method (Gutmann 2001). A multi-objective evolutionary algorithm was also 
investigated recently for possible use in crop-planning models (Sarker and Ray 2009). When the objective function is nonlinear and non-convex, as occurs in many applications in natural resource modelling, there may be multiple minima, thus precluding the use of many standard non-linear programming methods (see also discussions by Törn and Žilinskas 1987; Duan et al. 1996; Gutmann 2001). Some iterative non-linear methods, such as simulated annealing and genetic algorithms, can be effective for increasing the chance of finding the global solution, but tend to have slow rates of convergence (Gutmann 2001).

For the application in this study, many of the optimisation methods listed above have limited use, due to one or more of the following reasons

- The objective function, and also the constraints, may be real and non-linear (and the model must have the capability for expansion in scale and complexity).

- There may be multiple optima due to the high dimensionality of the problem.

- Treatment of ties in feasible values for map cells will need logical operations for resolution.

- The simulation model must be statistical in nature in order to provide for future risk assessment and uncertainty analysis.

- The proposed procedure needs to be capable of providing visualisation of the results in the form of a segmented map of the region.

These constraints serve to narrow the choice of possible approaches, especially when compatibility with risk assessment and uncertainty analysis are required.

The aims of the current investigation were (a) to investigate increasing the revenue for the South West Region of Victoria by optimising the allocation of crops, and (b) to develop a general modelling framework for the spatial allocation of commodity production over a region, subject to the modelling constraints (with a view to future expansion in complexity of the objective function and constraints). The primary model inputs in the current study consisted of GIS-based land suitability maps computed for a range of crops and their associated market prices. The model output was the optimum amount produced, together with the geographic location and the spatial extent of each agricultural crop on the optimised solution map. The model output also provides both statistical results and visualisation in the form of image segmentation into the various crop classes (where segmentation is based on economic factors rather than visual attributes, such as texture, as investigated by Benke et al. (1988). The approach was demonstrated on a set of data consisting of eight commodities with land suitability maps provided by a supporting study (Sposito et al. 2008). A salient feature of the approach is its capacity for expansion to include more detailed and complex formulations, constraints and sub-models. 


\subsection{Area of Study}

The model for land use allocation was applied to the South West Region of Victoria in Australia (also known as the Corangamite and Glen Hopkin Region). The Victorian economy provides a quarter of the total gross value of national agricultural production (Gunasekera et al. 2007). Agriculture is an important part of the regional economy and the region itself is experiencing increasing variability in land use as a consequence of changing climate. Land used for animal production is also allocated to horticulture and a variety of grain crops and pastures. The eight crops and pastures in the analysis represent a significant proportion of the total annual agricultural production of the region (see also Table 1)

\subsection{Materials and Software}

The software package developed for this project is referred to as (C) CropOptimizer 2.0 and is under continuing development. The original version was developed in Visual Basic by Wyatt $(2006,2008)$ and then later extended to include added optimisation options (Benke et al. 2011). Its current features include land spatial allocation by probabilistic optimisation or genetic programming, with provision of full maps and output tables for further implementation in economic models. The user interface permits map zooming and both spatial visualisation and numerical outputs. Data sources in the study were the Australian Bureau of Statistics for economic data (ABS 2008), and the Department of Primary Industries, State Government of Victoria, for land suitability data (Sposito et al. 2008). This latter dataset was produced using a multi-criteria analysis approach, the so-called Analytic Hierarchical Process or AHP (Saaty 1994), implemented using Model Builder in ArcView GIS (@ ESRI).

\section{Computational Approach}

\subsection{Revenue Optimisation}

The range of optimisation approaches available is reduced by the requirement for future risk assessment and uncertainty analysis, and the possibility of non-linear objective functions or constraints (in the sub-models), the use of real numbers and high dimensionality. A statistics-based approach covers many of the requirements, especially future analysis of errors in inputs and the possibility of confidence intervals for the outputs. The basic modelling framework is required to cater for future expansion to include a variety of new inputs, which could include market saturation effects, effects of changing climatic conditions and environmental trade-offs. 
For revenue maximisation based on optimisation of a primary set of inputs (e.g. land suitability), the objective function can be stated more formally as

$$
\begin{array}{lll}
\text { Maximise } & R=R[\mathbf{S}] \quad \text { where } R \in \mathfrak{R}^{+} \\
\text {Subject to: } & \mathbf{S} \in \Omega^{m} \quad \text { where } \Omega^{m} \subseteq \mathfrak{R}^{+}
\end{array}
$$

where $\Omega^{m}$ is the subspace defining the feasible region in an $m$-dimensional Euclidean space of positive real numbers, $\mathfrak{R}^{+}$, and the parameter set of size $m$ is given by $\mathbf{S}=\left\{s_{c}(a, b)\right\}$. Application of a probabilistic optimisation procedure leads to parameter selection in a probabilistic sense. In the course of the optimisation process, convergence to the optimum parameter set $\mathbf{S}_{\text {opt }}$ occurs after $k$ iterations, so that for arbitrarily small $\delta>0$,

$$
p\left(\mathbf{S}(k)-\mathbf{S}_{\text {opt }} \|>\delta\right) \rightarrow 0 \text { as } k \rightarrow \infty
$$

In the case of land suitability, and the maximisation of total revenue,

$$
\mathbf{S}_{\mathrm{opt}}=\left\{s_{c}(a, b)\right\}_{\text {opt }}=\underset{s_{c}(a, b) \in\left[a^{\prime}, b^{\prime}\right]}{\arg \max } R \text { where } R \in \mathfrak{R}^{+}
$$

where the values $s_{c}(a, b)$ occur in the range $\left[a^{\prime}, b^{\prime}\right]$. Probabilistic search methods are applicable to problems with non-linear objective functions and constraints, they are global in nature (less likely to be trapped in local solutions) and less affected by the starting point and increasing dimensionality (Törn and Žilinskas 1987; Duan et al. 1992; Törn et al. 1999).

Consider the case where the region is sub-divided into a large number of small cells of edge length $d_{e}$ with spatial reference $(a, b)$. For a specified commodity or crop type, denoted by the subscript, $c$, grown in cell $(a, b)$, the annual yield and net revenue is provided in a pilot study by (Benke et al. 2011):

$$
\begin{aligned}
& y_{c}(a, b)=Q_{c}(a, b) \times s_{c}(a, b) \\
& r_{c}(a, b)=P_{c}(a, b) \times y_{c}(a, b)-C_{c}(a, b)
\end{aligned}
$$

where $y_{c}(a, b)$ is the yield, $Q_{c}(a, b)$ is the maximum production quantity, and $s_{c}(a, b)$ is the land suitability (a fractional quantity), $\forall c \in N$, where $N=\left\{1,2 \ldots N^{\prime}\right\} ; a \in A$, where $A=\{1,2 \ldots A$ ' \} ; and $b \in B$, where $B=\left\{1,2 \ldots B^{\prime}\right\}$. Also, $r_{c}(a, b)$ is the net revenue, $P_{c}(a, b)$ is the market price of the commodity, and $C_{c}(a, b)$ is the cost of production. Values for $s_{c}(a, b)$ are provided by either multicriteria decision analysis (Saaty 1994) or a biophysical model (see references cited by Benke 2011). If $s_{c}(a, b)$ represents land suitability (Hossain et al. 2006; Sposito et al, 2008), maps are available 
showing the spatial variability for each crop type (e.g. see Figures 1 and 2 for lucerne and winter wheat), and the crop land suitability maps overlaid on the regional map therefore represent a 3D lookup table (3D-LUT). Each cell in a hypothetical optimised map would have associated categorical data for crop type and numerical data for land suitability.

Total net revenue, $R$, for the entire region, which is not rectangular in area and bounded by an irregular contour, is given more explicitly by

$$
R=\sum_{a \in A} \sum_{b \in B} r_{c}(a, b)=\sum_{a \in A} \sum_{b \in B} \mathbf{P}_{c}(a, b) y_{c}(a, b)-C_{c}(a, b)_{-}^{-} \forall c \in N(\text { index forcrop type) }
$$

The maximum revenue for the region is given by the objective function,

$$
\text { Maximise } R=\sum_{a \in A} \sum_{b \in B} P_{c}(a, b) y_{c}(a, b)-\sum_{a \in A} \sum_{b \in B} C_{c}(a, b)
$$

Subject to:

$$
\begin{aligned}
& s_{c}(a, b)= \begin{cases}s_{c 1}(a, b) & \text { if } P_{c 1}(a, b) Q_{c 1}(a, b) s_{c 1}(a, b)>P_{c 1 \neq c 2}(a, b) Q_{c 1 \neq c 2}(a, b) s_{c 1 \neq c 2}(a, b) \\
s_{c 2}(a, b) & \text { Otherwise }\end{cases} \\
& s_{c 2}(a, b)>s_{c 1}(a, b) \\
& s_{c L} \leq s_{c}(a, b) \leq s_{c U} \\
& s_{c L}, s_{c}, s_{c U} \in \mathfrak{R}^{+} ; c, c 1, c 2 \in N \text { crop types }
\end{aligned}
$$

where $s_{c L}$ and $s_{c U}$ are lower and upper bounds on land suitability for each crop type, $c$, and $\mathrm{s}_{c l}$ and $\mathrm{s}_{c 2}$ represent any two selections from the set of crop types, and the conditional statement is used to break ties in land suitability between crops at the cell level. The second term in the objective function represents the cost base that is held constant for this pilot study, and there are appropriate range constraints on the variables. The optimisation objective in the present case is to place the appropriate crop in the appropriate cell, subject to market price and range constraints, in order to maximise the total revenue for the region, i.e. we are dealing with a resource allocation problem with respect to crop location -- where a choice of crop is made for each cell in the region.

The dynamics of the problem are such that the net revenue varies spatially from cell to cell, depending on the combination of crop type, and its land suitability, market price and production cost. For example, for constant cost, the maximum cell revenue is dependent on the arithmetic product of price and land suitability, so that the most suitable crop may be discarded if its market price is too low. 
Later it will be evident that, during the course of the iterative optimisation process, emergent patterns of homogeneous regions are revealed - indicating optimum segmentation of the region. In the final map, representing the solution space of a proposed optimisation, the crop type may have changed unpredictably from cell to cell, and the number of cells finally allocated will vary from crop to crop, but this is only revealed at the end of the optimisation process.

\subsection{Costs of production}

The cost of production $C_{\mathrm{c}}(a, b)$ can be resolved into component costs, or sub-models for costs, e.g.

$$
C_{c}(a, b)=E_{c}(a, b)+F_{c}(a, b)+L_{c}(a, b)+S_{c}(a, b)+T_{c}(a, b)+W_{c}(a, b)+\ldots
$$

where

$$
\begin{aligned}
& E_{c}(a, b)=\text { Cost of energy (inputs) } \\
& F_{c}(a, b)=\text { Cost of fertilisers (nitrogen, potassium, phosphorus) } \\
& L_{c}(a, b)=\text { Cost of labour (over the full cycle) } \\
& S_{c}(\mathrm{a}, \mathrm{b})=\text { Cost of storage (following harvest) } \\
& T_{c}(a, b)=\text { Cost of transportation to silo } \\
& W_{c}(a, b)=\text { Cost of water for irrigation }
\end{aligned}
$$

Each of the cost categories in Eqn (10) may be replaced by a sub-model, and future updates to each sub-model could include explicit non-linear functions with direct connections to sub-model variables or parameters. For example, the source and nature of the water supply cost model, $W_{c}(a, b)$, which may be based on the supply volume multiplied by tariff rate, could include the effects of rainfall collection, groundwater, or external supply by interstate pipeline or desalination plant. The hydrological model for streamflow could also include non-linear flux equations, linking model parameters to water supply directly in a functional relationship (by streamflow), enabling analysis of sensitivity to calibration error and uncertainty analysis. In a similar manner, control parameters in the desalination plant could be directly linked to the global revenue stream, again providing potential for sensitivity analysis and uncertainty analysis.

Road transportation costs, $T_{c}(a, b)$, may also be encapsulated in a cost sub-model. Following harvesting and dispatch to the silo, haulage costs may be referenced to a logistics model based on cartage rate and geographical location. Such a model could be derived from first principles, or based on a transportation modelling approach from operations research (Hillier and Lieberman 2004). Ultimately, given sufficient resources, a highly resolved model would reference the actual road networks between the cells or groups of cells (using GPS data), or the exit roads from the resulting segmented 
homogeneous cell regions (crop types), relative to the silo location. Pending the availability of sufficient data, transportation cost could be initially approximated by the product of the cartage road rate $(\$ / \mathrm{km})$ and the Euclidean distance between each production cell and the silo location, using the theorem of Pythagoras, e.g.

$$
\begin{aligned}
& T_{c}(a, b)=t_{c}(a, b) \times d_{c}(a, b) \\
& d_{c}(a, b)=\sqrt{4_{d e}-x_{o r}^{2}+y_{d e}-y_{o r}^{2}}
\end{aligned}
$$

where,

$$
\begin{aligned}
& T_{c}(a, b)=\text { transportation cost for commodity } c \\
& t_{c}(a, b)=\text { transportation cost rate in } \$ / \mathrm{km} \\
& d_{c}(a, b)=\text { Euclidean distance between cell and silo location } \\
& x_{d e}=x \text {-coord of destination (silo) } \\
& x_{o r}=x \text {-coord of origin (cell) } \\
& y_{d e}=y \text {-coord of destination (silo) } \\
& y_{o r}=y \text {-coord of origin (cell) }
\end{aligned}
$$

The cost of fertiliser (nitrogen, potassium, phosphorus) may be accounted for by incorporation of a nutrient-based cost sub-model, using a systems-based approach originating from planning and management procedures at the farming or paddock level. In summary, many of the constraints limiting revenue optimisation can be accounted for by additional cost sub-models, including also potentially an emission trading scheme (ETS) for carbon credits, and various socioeconomic factors which introduce additional uncertainties (Herath and Prato 2006).

\subsection{Model Simplification for Case Study}

In the current situation, for the purpose of demonstration of the modelling framework, some simplifications are possible. Assuming that the cost base is relatively fixed and very low in magnitude (noting that the production costs for the region were estimated at around 5\% of gross revenue, according to ABS 2008), then the $C_{i j}$ term can be held constant for the purpose of maximisation. The objective function is thus simplified to :

$$
\max R \cong \sum_{a \in A} \sum_{b \in B} P_{c}(a, b) y_{c}(a, b)=\sum_{a \in A} \sum_{b \in B} P_{c}(a, b) Q_{c}(a, b) s_{c}(a, b)
$$

The important variables for crop selection are the arithmetic product of land suitability, quantity and market price for each crop classification and their spatial fluctuations across the region. In the final optimum solution map, some values of $s_{c}(a, b)$ selected from the 3D-LUT may be repeated and even 
concatenated over different cells. In the course of the optimisation, logical operations may be required on some cells, such the resolution of tied values selected from the LUT.

For any given cell, land suitability data are available for eight crops (in this experiment, but subject to future expansion), with possible ties causing further processing issues if no cell sub-division is allowed. Because of this uncertainty, and to allow for scaling-up, and real values with non-linear constraints, the deterministic variable for land suitability is solved by an iterative probabilistic method. Treating the land suitability variable as a random variable means that the cell revenue also has a probabilistic value, so it follows that, each pass, $k$, over all cells in the region represents a sample from a probability distribution of $R$, i.e.

$$
p(R)=p\left(\sum_{a \in A} \sum_{b \in B} P_{c}(a, b) Q_{c}(a, b) s_{c}(a, b)\right)
$$

If the distribution is sampled repeatedly, over all commodities, and over $n$ cells, using probabilistic simulation, for a prescribed number of iterations, $k=1 \ldots r$, then the output distribution of $p(R)$ has values representing a range of estimates for the total revenue, i.e. the revenue model, $\mathbf{R}$, for estimation of the mean revenue (or expectation value) and the maximum revenue can be expressed in compact notation as

$$
\begin{aligned}
& \mathbf{R}_{\text {mean }}=E(R)=\sum_{k=1}^{r} R_{k} p\left(R_{k}\right) \\
& \mathbf{R}_{\text {max }}=\max \boldsymbol{R}_{k}
\end{aligned}
$$

This optimisation of the land allocation is carried out by the process of probabilistic simulation and optimisation (Fishman 1995, Rubinstein and Kroese 2007). The desired output consists of a commodity segmentation map showing the optimum location of different commodities for production in the region, together with a list of the optimum production quantities and an estimate of the total revenue. For enhanced speed of convergence, various reinforcement strategies are available, especially when more variables are involved (e.g. see Skinner et al. 1990).

Unlike traditional Monte Carlo simulation, the feasible values for land suitability are not generated from a probability distribution with lower and upper bounds, but rather are selected (using the uniform distribution) from the 3D-LUT. The computational expense of this operation increases linearly with the number of crop types included in the LUT, and quadratically with increasing map resolution (i.e. smaller cell size). If cost models are also included, then the increase in computational expense is dependent on the complexity and possible non-linearities involved (especially if direct linkage to a cost model parameter is involved). 
Comparison of the optimum result with the expected or existing allocation, by means of the convergence plot, provides an indication of the percentage increase in revenue possible by using the optimal allocation algorithm. An advantage of a probabilistic approach for natural resource allocation is the potential to provide information on quantitative risk assessment and uncertainty analysis, by providing a simulation-based predictive model, in addition to optimisation (Benke et al. 2008). Probabilistic methods also provide a global search capability and are particularly suitable for highdimensional non-linear functions with real parameter values, which are also characteristic of many natural resource models (Duan et al. 1992).

A probabilistic approach has an advantage in the treatment of tied values of $s_{c}(a, b)$ selected from the set of input crop maps as feasible values for the solution map. Each cell will have eight land suitability values competing for acceptance (from eight different crop types, $N^{\prime}=8$ ). If several crop types produce the same numerical value for land suitability (which is not uncommon), then one might naively use the logical process

$$
s_{c}(a, b)=\operatorname{Max}\left\{s_{c}(a, b) \in \mathfrak{R}^{+}: c=1 \ldots N^{\prime}\right\}
$$

This approach, however, fails to account for instances where, at some locations, certain crops of high land suitability may have low market prices and therefore produce lower revenue than the reverse situation, i.e. less suitable crops with high market prices. The more effective approach is a conditional test that also serves as a constraint, i.e. simplifying the expression in Eqn (8),

$$
s(a, b)= \begin{cases}s_{\max }(a, b) & \text { if } \quad P(a, b) y(a, b)=\max \left\{P_{c}(a, b) y_{c}(a, b)\right\} \\ s(a, b) & \text { Otherwise }\end{cases}
$$

where. the correct decision for breaking ties is on the basis of contribution to cell revenue, $r_{c}(a, b)$. If there were no global regional constraints or other external factors, and uncertainty analysis was not required (i.e. requiring stochastic simulation), then optimisation is therefore possible in a deterministic sense by maximising revenue per cell and summing all cells in the region. Even with this comparison, however, there may be ties on some rare occasions. The tie is then broken by a random choice, a process which is subject to an averaging effect over a large number of trials in the simulation. The logic in Eqn (18) also effectively states that land suitability on its own is insufficient as a metric for crop choice for revenue optimisation.

\subsection{Convergence of Simulation}


The minimum number of iterations required for probabilistic simulation in the estimation of the mean value is useful for two principal reasons. If the number of iterations is too low, convergence will not have occurred for sufficient accuracy, whilst a very large iteration count may add significantly to the experimental cost (in resources used, such as computer time and memory). Define the error, $\varepsilon$, as the difference between the observed sample mean, $\bar{x}$, and the true value of the population mean, $\mu(x)$, and also the standard normal parameter, $z$, as

$$
\varepsilon=\bar{x}-\mu(x) \quad ; \quad z=\frac{x-\mu(x)}{\sigma(x)}
$$

If $\bar{x}$ is the estimate of $\mu(x)$, then one can be (1- $\theta) 100 \%$ confident that the error will be bound by the following expression for $\varepsilon$, which can then be solved for the number of iterations, $k$, required for the specified confidence and margin of error (precision) for the mean,

$$
\varepsilon<z_{\theta / 2} \cdot \frac{\sigma(x)}{\sqrt{k}} \Rightarrow k=\left[z_{\theta / 2} \cdot \frac{\sigma(x)}{\varepsilon}\right]^{2}
$$

In practice, this expression requires the specification of the level of confidence and the standard deviation must be provided or estimated from a small number of iterations in a pilot run, i.e. assume $s(x) \approx \sigma(x)$. The acceptable error, $\varepsilon$, between the means of the sample and population must be specified. The Student $t$-statistic, rather than the normal distribution, should be used if the number of iterations in the pilot run is less than $n \approx 30$. Further discussion on this issue can be found in the statistics literature (Walpole 1968; Freund 1998).

The foregoing treatment is relevant to execution of the revenue model as a simulation for the purpose of revenue prediction. When the objective of the exercise is optimisation, the requirement is for the maximum value from the simulation output distribution. The sampling distribution describing the means does not necessarily follow the same form as the sampling distribution describing the maximum. Estimation of the minimum number of iterations required for convergence to a stable value in the latter case can be calculated in an empirical manner by a method similar to that proposed by Robinson (2005), and is based on defining the error bound as follows,

$$
\varepsilon<\frac{1}{m} \sum_{\gamma=1}^{m}\left|y_{\gamma+k+1}-y_{\gamma+k}\right|
$$


which is the absolute difference between successive outputs $k$ in the pilot simulation, averaged over a moving window of size $m$. The minimum number of iterations is determined when the value of $\varepsilon$ drops below a pre-assigned value for a specified number of iterations, for example, $\varepsilon<1 \%$ for 100 iterations. Robinson also introduced additional operations for improving smoothness and convergence criteria for use in automated analysis of simulation data. This criterion may also be used for a more refined estimate of the number of iterations required for the mean output described in the previous section.

An alternative approach is to fit a model to the convergence plot of the optimisation of revenue. If the plot is smooth, continuous and reproducible, and not subject to 'jumps' suggesting transitions to local extrema, then the following empirical result is convenient,

$$
R=\alpha+\beta\left[-\exp (-\delta k)_{-}^{-}\right.
$$

This equation is analogous to a capacitor charging curve with asymptotic behaviour and saturation, and is typical of the convergence curves observed in this type of stochastic optimisation. The parameters $\alpha, \beta$, and $\delta$ are determined by non-linear regression analysis, using an appropriate iterative method. Furthermore, as the number of iterations increases, the estimate for revenue tends to a limiting value, i.e.,

$$
\text { As } k \rightarrow \infty, R \rightarrow \alpha+\beta
$$

Therefore, given a close fit to the plot of simulation outputs, the optimum revenue can be estimated as $R=\alpha+\beta$. Alternatively, when not using the convergence model, the optimisation process can be halted and evaluated after a specified number of iterations, subject to a stopping rule analogous to Eqn (21) and a specified precision (i.e. reduction in percentage change in successive iterations).

\section{Method}

The South West Region in Victoria has a breadth and depth of several hundred kilometres in each orthogonal dimension. The area under consideration for the study was sub-divided into 1800 cells of size $5 \times 5 \mathrm{~km}$, representing an area of about $45,000 \mathrm{sq} . \mathrm{km}$. The cell size was consistent with the resolution used for studies of land suitability and climate change undertaken elsewhere (Sposito et al. 2008). The search for the optimum crop for each cell, on the basis of maximising total regional revenue, was equivalent to an optimisation problem with 1800 unknowns. Market prices for the eight crops originated from estimates based on data from the Bureau of Statistics (ABS 2008), but were assumed to be spatially invariant (i.e. $P_{c}(a, b)=P_{c}$ ), as it was not feasible or relevant in this study to 
have market price data resolved down to the cell level. The LUT was populated with land suitability data referenced from Sposito et al. (2008).

The data for each land suitability map, for each crop type, was obtained using AHP, which is a multicriteria analysis approach (Saaty 1994), and was implemented using Model Builder in ArcView GIS (C ESRI) as described by Sposito et al. (2008). The input consisted of maps of the region representing various criteria (including biophysical data, soil attributes, landscape data, climate data and expert opinion). Each map, representing a single criterion, was reclassified according to the AHP rating and multiplied by the AHP weight (Pelizaro et al. 2010). The criterion maps were overlaid, and finally summed up according to the hierarchy level to a final composite index map. The final output map ranked areas in terms of suitability for the growth of the commodity under consideration (for example, see Figures 1 and 2, which show land suitability maps for lucerne and winter wheat). Productivity of a particular area can be estimated by multiplying the maximum yield defined at the apex of the AHP hierarchy by the suitability index, e.g. if an area shows a suitability index equal to 8 for winter wheat, a yield of $(0.8 \times 10=) 8$ ton/ha/year is expected to be achieved in that area (for more details, see

Pelizaro et al. 2010). The process was repeated for each of the eight commodities in the study, producing eight land suitability maps.

In the simulation, each neighbourhood cell had its commodity type and land suitability value selected probabilistically (Benke et al. 2011). This eliminated the problem of treatment of ties for land suitability for competing crops within each cell, where each may have had the same land suitability at that geographical location (i.e the LUT for each cell had eight land suitabilities from eight crops). It also avoided the need for proportional cell sub-division, which introduces complexity in processing and may add a more finely resolved pepper-and-salt texture to the map segmentation. This last problem can make comparisons with conventional land suitability maps more difficult by producing unwanted small and often disconnected regions in the segmentation.

\section{Experimental Results and Discussion}

\subsection{Optimisation Results}

The revenue varies spatially, from cell to cell, depending on the combination of price and land suitability - and these values are changed probabilistically for the entire map, after each iteration in the optimisation process. Figures 3, 4, 5 and 6 show the course of the optimisation. The program interface for (C) CropOptimizer 2.0 (Wyatt 2006; Benke et al. 2011) developed for this purpose reveals the evolution of the solution map over many iterations. Inspection of the map after the final iteration in the optimisation process reveals striking homogeneity within the segmented regions, which is perhaps an emergent property of system complexity (cf. Figure 3 with Figure 6). There is almost no pepper- 
and-salt noise evident (even at lower iteration counts), despite each cell being adjusted independently to maximise the global revenue (i.e. assuming no cell-to-cell correlation). The final map of crop segmentation for the region also provides a visualisation of the optimum results for land allocation. One noteworthy feature is that the optimisation process discarded some crops from consideration, such as barley, which may have implications unrelated to a purely computational solution, such as consumer demand.

The convergence behaviour of the model output for total revenue is shown in Figure 7. A curve was fitted to the data by non-linear regression using Eqn (22), where the parameters were obtained from the Levenburg-Marquardt technique for error minimisation (Gill et al. 1981). The parameters were determined as $\alpha=1043.49, \beta=580.73$, and $\delta=0.1548$. The associated regression statistics were: $r^{2}=$ 0.998 (d.f. adjusted $r^{2}=0.997$, s.e. $=7.00, F$-value $=2296.68$ ). An estimate of the simulation mean was $\$ 1493$ million, noting that 433 iterations are required to obtain a precision of about $1 \%$ from Eqn (20). With respect to optimisation, from Eqns (22) and (23), the maximum possible total revenue in this simulation was determined as $R=\alpha+\beta$, i.e. $R \approx \$ 1624$ million (representing an improvement over the range of plotted values of over $\$ 400$ million).

The foregoing statistics, together with inspection of the convergence plot in Figure 7, reveal very little scatter about the fitted curve (errors between fitted curve and plotted data were all less than 1\%). This smooth convergence suggests that the stopping rule proposed by Robinson in Eqn (21) is not necessary in this simple baseline revenue model. This rule is more appropriate for noisy or nonsmooth data, where the search space may also contain random jumps to multiple maxima, in which case global search algorithms are necessary (Benke and Skinner 1994; Benke 2000). In the present case, the model given by Eqn (22) is preferable, especially in that it estimates the maximum value itself directly rather than the number of iterations required for a specified precision. Future additions and refinements to the current objective function may lead to new convergence behaviour and new comparisons, so that this result is not definitive.

Figures 8 shows the current regional allocation of crops, by proportion (\%), and also a near-optimal allocation after 49 iterations in the optimisation process. The interesting result is that for the purpose of optimising total revenue, the motivation would be to reduce the commodity types grown from eight to three (lucerne, ryegrass and winter wheat). This is, however, a numerical result as a consequence of using an optimisation procedure based on prescribed inputs and constraints. There may be other reasons for growing certain crops that have been eliminated, but may be borderline in acceptance (and would reduce the optimum result by a very small amount only). Their inclusion may be justified for social reasons, such as employment considerations, or for landscape sustainability or water conservation. An optimisation tool therefore must be used with caution, and be regarded as an adjunct 
to policy development and decision making, in the context of systems thinking, rather than constrained by a narrow reductionist basis.

The convergence plot in Figure 7 reveals that an improvement of the order of $30 \%$ in total gross revenue is possible, even over the range of the plotted values alone, subject to the caveats in the last paragraph. It is clear that even with this simple baseline model for regional revenue, quite substantial improvements in regional income are possible. Other effects of significance requiring future investigation relate to economic factors, such as market saturation effects on prices due to demand and supply constraints, and the various inputs affecting the cost base.

In Table 1, the value of the agricultural production for 2006-7 in the South West Region of Victoria is provided by the Australian Bureau of Statistics (ABS 2008). The commodities included in this figure include pasture and broad-acre crops (including the eight commodities in this study), horticulture (vegetables, fruit and nuts) and livestock (sheep, cattle and pigs). The gross value of agricultural commodities produced is defined as the value placed on recorded production at the wholesale prices realised in the market place. The ABS also defines the local value of commodities produced as the value placed on commodities at the point of production, such as the farm gate. This figure is produced by deducting marketing costs from the gross value of commodities produced. It is cautioned that gross and local value of agricultural commodities produced involve some duplication as they include certain agricultural commodities which are consumed as raw materials to produce other agricultural commodities, such as hay for livestock.

There are two aspects of the ABS data which require further elaboration (Table 1). First, the difference between gross value and local value is not large (suggesting a cost base in the order of about 5\%) which supports using gross value as a reasonable approximation for exploring the optimal allocation problem (until more detailed statistics on costs are available). The second point of note is that the total agricultural production for the region in 2006-7 is in the region of $\$ 2$ billion. Current land-use for the sub-category of the pasture crops in this study has an estimated total revenue of around $20 \%$ of the total agricultural production and there is scope to improve the theoretical annual value of agricultural production in this sub-category alone by a significant amount through optimisation of land use allocation. This potential improvement suggests further research in optimising land allocation can be reasonably justified due to the possibility of substantial benefits to the stakeholders, which would include farmers, shareholders and the Federal Government (through taxation).

\subsection{Constraints on Results and Policy Implications}

In the pilot study by Benke et al. (2011), some constraints on optimisation were discussed and are repeated and elaborated further in this section. In practice, covering the South West region with 
ryegrass would expand the supply of this commodity to the point that its price may fall to quantities that may be less than commercial in nature. It is only in those areas where the soil is distinctly unsuitable for growing ryegrass, and where yields will be consequently very low, that other commodities would become relatively more profitable, such as winter wheat and lucerne. In short, the mathematically optimal solution from this simulation is the theoretically ideal case only, and reveals that the production of ryegrass dominates in the absence of constraining factors. One possible constraining factor is the effect of market saturation on commodity prices due to over-production. A possible market saturation model could be based on a hyperbolic relationship between price and production, i.e. converting price to a variable that is updated during the course of the optimisation process:

$$
P_{c}(a, b)=\frac{K}{Q_{c}(a, b) \times s_{c}(a, b)}
$$

Whilst we have both price and production data available for a defined year from ABS statistics, which provides a calibration point for solving for the constant, $K$, there are other issues requiring resolution. For example, after how many iterations in each simulation should the price data be updated with this model, and are there interactions and correlations with other commodities? These issues are subjects for further research.

Adding bounds on the movements of future commodity prices supports a more constrained optimisation process. An economist may set reasonable limits, such as an initial hard constraint of $\pm 10 \%$ for the price change per annum. Ryegrass is used for both pasture and hay for grazing animals (sheep and cows) and is therefore a cost input for both the lamb and dairy industries, which have a combined export value in Victoria of about $\$ 3$ billion per annum (DPI 2011). Unconstrained production may lower the price in the following year but, for the livestock industries, also lowers input costs and therefore increases productivity. This highlights a difficulty in a reductionist approach, as opposed to a systems-based (or holistic) approach, which is more effective at a regional level but has increased complexity.

There is also the issue of price and demand elasticity, which is the domain of economic modelling (Gillespie, 2007). This effect adds further complexity and highlights the potential of linking the optimisation approach to an economic model. For example, a coefficient of price elasticity of demand for a commodity, $c_{p / d}$, may be given by a simple standard expression of the following general form 


$$
c_{p / d}=\frac{\Delta V_{d} / V_{d}}{\Delta P_{c} / P_{c}}
$$

The numerator represents $\%$ change in the quantity demanded, and the denominator represents $\%$ change in the price. This may have both positive and negative values and has utility in the determination of future price movements as a soft constraint in time-series optimisation. It requires information, however, on the level of demand in the marketplace and also introduces the prospect of interactive optimisation (see also Gillespie, 2007). Incorporation of the optimisation engine into an economic model has the advantage of exposing underlying behaviour and insights not otherwise visible. There is therefore potential and motivation for the optimisation procedure to be used as a computational engine incorporated into a larger economic model, rather than exclusive use as a standalone procedure.

In Australia, the Productivity Commission supports the development of process and evidence-based approaches to policy development - which include data gathering, quantitative techniques, surveys and trials analysis (Banks et al. 2010). The use of quantitative techniques, such as optimisation and regression modelling, is required for the construction of computer models with predictive capabilities. Optimisation of land use by computer modelling and evaluation of alternative scenarios raises issues relating to strategy and policy. For example, given the optimal spatial allocation of commodities, what incentives are there for convincing individual farmers to change the nature and mix of commodity production? Would farmers be receptive to the idea of producing a monoculture rather than pursue mixed-use farming?

For further elaboration on this point, maximisation of revenue across a region, such as the Corangamite-Glen Hopkin Region, produced an optimum allocation of commodities subject to land suitability and market prices. The results of the simulation showed that total revenue from the region could be increased notionally by at least $30 \%$ in value. Therefore, a significant increase in commodity production is possible if farmers were cooperative in commodity production - in contrast to having farmers growing different crops, at random, and unrelated to land suitability or market price.

Critics may claim that such cooperation is unrealistic - and this opens the debate on the merits of the unregulated market versus a planned market. One way to achieve cooperative production, anonymously and implicitly, is to provide the farmer with a map of optimum allocation on an annual basis, based on land suitability and current market prices. The farmer uses this as a decision support aid and has discretion for the final choice of commodity mix. Such a decision support aid would allow the farmer to decide which commodities appear to have potential for the most profit, noting that 
annual market prices capture implicitly other factors, such as demand and transportation costs. The farmer would be aware that the computer model is not an automatic solution but a decision support aid -- and would introduce expert opinion into the choice. Modifying factors would include personal judgement on possible pest-induced crop losses, soil degradation and crop rotation issues, price signals from previous annual trends or macroeconomic information in the mass media.

A salient feature of the optimisation model is that it produces a first approximation to the estimate of what to grow, where to grow it, and how much to grow. In addition, it produces a table and regional map showing the predicted optimum tonnage and spatial extent for each commodity produced. Previously, no such information was readily available and the policy analyst or farmer was limited to his own judgement and knowledge. The estimate produced for the static case with current prices can easily be repeated each year to produce the dynamic case for time-series analysis. Each step in the time-series will have new annual inputs for price and land suitability data.

\subsection{Software Engineering Issues}

The (C) CropOptimizer 2.0 software (Wyatt 2006; Benke et al. 2011)) currently provides no landscape imagery and would benefit from further map layers such as temperature and rainfall for improved contextual visualisation of the data. These capabilities could be realised using third-party commercial off-the-shelf (COTS) software. The package could be modified to export the geospatial data as Keyhole Markup Language (KML) output for Google Earth. This would then appear as a layer in the Google Earth client superimposed on the map alongside other relevant map layers. For ease of use the software would benefit from implementation as a web service, to enable users to adjust settings from inside Google Earth via the browser pane. Other potential viewers include ESRI ArcMap and $u$ Dig, an open source desktop GIS tool based on the Eclipse RCP platform. For ease of use with these software packages the (C) CropOptimizer 2.0 tool could be implemented as a plug-in, in C\# for ArcMap or Java for Eclipse RCP.

\subsection{Future Risk Assessment}

One reason for the approach taken in this simulation is the possibility of future uncertainty analysis. Recent work undertaken by the authors has revealed that aleatory uncertainty (variability) in land suitability values can be analysed by means of statistical simulation methods based on Monte Carlo simulation (Pelizaro et al. 2010; Benke and Pelizaro 2010). In this case, each land suitability value in the 3D-LUT would be replaced by a probability distribution and the optimisation model executed as described in this paper. Repeated batch runs of the model would be sufficient to provide uncertainty bounds or metrics on the result, such as the standard deviation or confidence interval. Risk analysis is 
possible by means of referencing the cumulative distribution of the simulation. These issues are currently under investigation and part of a proposed global strategy for land use optimisation depicted in Figure 9.

\section{Summary and Conclusion}

Resource allocation and optimisation in rural production has been the subject of considerable research in the past decade (see, for example, Detlef and Jensen 2004; Weintraub and Romero 2006; Herath and Prato 2006; Koomen et al. 2007). Computer simulation studies of land use allocation have economic implications and support the conduct of natural resource management (Koomen et al. 2007, 2008). One objective of the current study was to investigate the possibility of an optimal or nearoptimal allocation of commodities across the South West Region of Victoria in southern Australia on the basis of revenue. The solution map contains both categorical data (commodity type) and numerical data (land suitability). Simulation results indicated that the optimal land allocation for the commodities could in principle lead to a potentially significant increase in revenue. The decision support system described here has potential to support policy makers and analysts in the planning phase of optimising regional agricultural production and allows for the quantification of the factors affecting the solution.

There are, however, many other issues to consider that add complexity and uncertainty, and these include the need to consider more real world constraints, both economic in nature and also social and environmental concerns. One example is the effect of market saturation on commodity prices due to over-production (which suggests consideration of such economic factors as supply and demand and the effects on price and production). The latter issues may be addressed by imposing constraints on price growth or running the model on an annual basis with new inputs. Modelling assumptions also include no significant correlation between cells, which may be an issue at very high cell resolutions. Also, there are subjective factors that may be involved, such as farmer crop preferences, which are not normally incorporated into objective functions. The approach is therefore a decision support aid rather than an automatic procedure and forms a framework for future development and systematic inclusion of further factors requiring consideration.

Another objective of the investigation was to develop the framework for a probabilistic simulation process designed to maximise revenue by optimising spatial allocation of commodities. The approach investigated produced commodity segmentation maps consistent in both appearance and structure with contemporary land suitability maps (as described by Hossain et al. 2006 or Pelizaro et al. 2010). The approach taken was chosen for a number of reasons, including (a) compatibility with future uncertainty analysis and risk assessment, (b) to allow for non-linear modifications in the cost function and constraints, (c) capability for scaling up to larger problems, as probabilistic algorithms are less 
affected by increasing dimensionality, (d) ability to cope with logical operations on map cells to resolve data ties or conflicts, and (e) to provide some capability for global performance, as future model development may lead to multiple optima which are associated with non-linearity and higher dimensionality. Although the baseline revenue model used was simple in nature, it was necessary to accommodate for the issues described above and to allow for future expansions with the inclusion of non-linear cost sub-models.

The prototype software package (CCropOptimizer 2.0 was used for optimising the allocation and exploring feasible solutions, providing visualisation of the optimal solution and a probabilistic search strategy (Wyatt 2006; 2008; Benke et al. 2011). Changes to the human-computer interface are being investigated to make the software more user-friendly and to enable future expansions in functionality. Refinement and further updating of the programmed objective function and constraints are possible, together with reinforcement rules for faster convergence for planned application to larger problems. Speed of convergence and choice and refinement of optimisation procedure are issues of importance with respect to scaling-up and higher dimensionality. The future incorporation into the software of risk and uncertainty metrics requires land suitability values and market prices with probability distributions. This approach has the potential to produce confidence intervals and risk assessments as additional outputs (Benke and Pelizaro 2010).

The software would benefit from further map layers, such as temperature and rainfall for improved contextual visualisation of the data. These capabilities could be realised using third-party commercial off-the-shelf (COTS) software. Furthermore, the software could be modified to export the geospatial data as Keyhole Markup Language (KML) output for Google Earth. This would then appear as a layer in the Google Earth client superimposed on the map alongside other relevant map layers. For ease of use the software would benefit from implementation as a web service, to enable users to adjust settings from inside Google Earth via the browser pane. Other potential viewers include ESRI ArcMap and $u$ Dig, an open source desktop GIS tool based on the Eclipse RCP platform.

In conclusion, a salient feature of using an optimisation framework is that it produces a first approximation to the estimate of what to grow, where to grow it, and how much to grow. Previously, the astute policy analyst or farmer would use his own judgement and knowledge without the potential advantage of a decision support aid. An optimisation procedure could be executed on an annual basis with new inputs for price and land suitability data. At the macro level, as favoured by the policy analyst, a significant increase in regional revenue is possible, subject to incentives, in contrast to having farmers growing different crops, at random, and unrelated to land suitability or market price. At the micro level, a farmer could be provided with an annual regional map of estimated optimum allocation as a decision support aid. Such a decision support aid would allow the farmer to decide 
which commodities appear to have potential for generating the most profit and allow him to combine this advice with personal discretion for the final choice of commodity mix.

\section{Acknowledgements}

The first author is grateful to Ray Wyatt and Victor Sposito for past discussions.

\section{References}

ABS (2008). Ref. 7125.0 - Agricultural Commodities: Small Area Data, Australia, 2006-07. Australian Bureau of Statistics, Update Dec. 4, 2008.

Banks, G., MacRae, A., Woods, M., Scott, P., Craik, W., Sylvan, L., Fitzgerald, R., Weickhardt, P. and Kalisch, D. (2010). Annual Report 2009-10, Productivity Commission, East Melbourne, VIC, Australia.

Bari, M. A. and Smettem, K. R. J. (2006). A daily salt balance model for stream salinity generation processes following partial clearing from forest to pasture. Hydrology and Earth System Sciences 10, 519-534.

Benke, K.K., Skinner, D.R. and Woodruff, C.J. (1988). Convolution Operators as a Basis for Objective Correlates of Texture Perception, IEEE Transactions on Systems, Man and Cybernetics, 18, 158-163.

Benke, K. K. and D. R. Skinner (1994). Texture Discrimination by Neural Networks and Global Optimization. AI Applications 8, 25-39.

Benke, K.K. (2000). Adaptation of Spatial Filtering Theory to the Estimation of Texture Element Size and Regularity, Computers and Electronics in Agriculture, 28, 187-194.

Benke, K.K., Lowell, K.E. and Hamilton, A.J. (2008). Parameter Uncertainty, Sensitivity Analysis and Prediction Error in a Water-Balance Hydrological Model, Mathematical and Computer Modelling, 47, 1134-1149.

Benke, K.K. and Pelizaro, C. (2010). A Spatial-Statistical Approach to the Visualisation of Uncertainty in Land Suitability Analysis, J. Spatial Science, 55, 257-272.

Benke, K.K., Wyatt, R. and Sposito, V.A. (2011). A Discrete Simulation Approach to Spatial Allocation of Commodity Production for Revenue Optimisation over a Local Region, J. Spatial Science, 56, 89-101.

Detlefsen, N.K. and Jensen, A.L. (2004). A Stochastic Model for Crop Variety Selection, Agricultural Systems, 81, 55-72.

DPI (2011), Victoria's Sheep Meat and Wool Industry - Winter 2011, Department of Primary Industries, http://www.dpi.vic.gov.au/agriculture/beef-and-sheep/sheep/victorias-sheep-meat-andwool-industry.

Duan, Q., Sorooshian, S. and Gupta, V. (1992). Effective and Efficient Global Optimisation for Conceptual Rainfall Runoff Models, Water Resources Research, 28, 1015-1031. 
Fischer, C., Kralisch, S., Krause, P., Fink, M. and Flügel, W.-A. (2009). Calibration of hydrological model parameters with the JAMS framework, $18^{\text {th }}$ World IMACS?MODSIM Congress, Cairns, Australia, 13-17 July.

Fishman, G. S. (1995). Monte Carlo: Concepts, Algorithms, and Applications. Springer, New York (USA).

Freund, J. E. (1998). Mathematical Statistics, Prentice-Hall, New Jersey (USA).

Gill, P. E., Murray, W. and Wright, M. H. (1981). The Levenberg-Marquardt Method. In Practical Optimization, pp 136-137. Academic Press, London (UK).

Gillespie, A. (2007). Foundations of Economics. Oxford Univ. Press, Oxford (UK).

Gunasekera, D. Kim, Y., Tulloh, C. and M. Ford (2007). Climate Change: impacts on Australia agriculture. Australian Commodities, 14(4), 657-676.

Gutmann, H. (2001). A Radial Basis Function Method for Global Optimization, Journal of Global Optimization, 16, 563-586.

Horst, R., Pardalos, P., Thoai, N. (2000). Introduction to Global Optimization, Kluwer Academic Publishers, Dordrecht, The Netherlands.

Hillier, F. and Lieberman, G. (2004). Introduction to Operations Research, McGraw-Hill (USA).

Herath, G. and Prato, T. (2006). Using Multi-Criteria Decision Analysis in Natural Resource Management, Ashgate Publishing Limited, Hampshire, England (UK).

Hossain, H., V. Sposito and Evans, C. (2006). Sustainable Land Resource Assessment in Regional and Urban Systems. Applied GIS 2(3), 24.1 - 24.21.

Koomen, E., Loonen, W., Hilferink, M. (2008). Climate-Change Adaptations in Land-Use Planning: A Scenario-Based Approach, In Bernard, L. (Ed.), The European Information Society: Taking Geoinformation Science One Step Further Springer, Dordrecht, The Netherlands.

Koomen, E., Stillwell, J., Bakema, A., Scholten, H.J. (2007). Modelling Land-Use Change: Progress and Applications, Springer, Dordrecht, The Netherlands.

Pelizaro, C., Benke, K. and Sposito, V. (2010). A Modelling Framework for Optimisation of Commodity Production by Minimising the Impact of Climate Change, Applied Spatial Analysis and Policy, 4, 201-222.

Robinson, S. (2005). Automated Analysis of Simulation Output Data. Pages 763 -770 in Eds. M. E. Kuhl, Steiger, M.N. Armstrong, F.B., Joines, J.A., Proceedings of the 2005 Winter Simulation Conference.

Rubinstein, R. Y. and Kroese, D. P. (2007). Simulation and the Monte Carlo Method, John Wiley and Sons, New York (USA).

Saaty, T. L. (1994). Fundamentals of Decision Making and Priority Theory with the Analytic Hierarchy Process, RWS Publications, Pittsburgh, (USA).

Sarker, R. and Ray, T. (2009). An Improved Evolutionary Algorithm for Solving Multi-Objective Crop Planning Models. Computers and Electronics in Agriculture 68, 191-199.

Said, Y.H. and Wegman, E.J. (2009). Road Map for Optimisation. Wiley Interdisciplinary Reviews: Computational Statistics, 1, 3-11. 
Skinner, D.R., Benke, K.K. and Chung, M.J. (1990). Application of Adaptive Convolution Masking to the Automation of Visual Inspection, IEEE Transactions on Robotics and Automation, 6, 123-127.

Soliman, O., Sarker, R.A., Zahir, S. (2008). Fuzzy Goal programming Model with Parametric Analysis For regional Sustainability Development under Climate Change. ASOR Bulletin 27, 2-15.

Sposito, V., Pelizaro, C., Benke, K., Anwar, M., Rees, D., Elsley, M., O’Leary, G., Wyatt, R. and Cullen, B. (2008). Climate Change Impacts on Agriculture and Forestry Systems in South West Victoria, Australia. Department of Primary Industries - Parkville Centre.

Törn, A., and Žilinskas, A. (1987). Global Optimization, Springer, Berlin (Germany).

Törn, A., Ali, M. and Viitanen, S. (1999). Stochastic Global Optimization: Problem Classes and Solution Techniques, Journal of Global Optimization 14, 437-447.

Walpole, R. E. (1968). Introduction to Statistics., Macmillan, New York (USA).

Weintraub, A. and Romero, C. (2006). Operations Research Models and Management of Agricultural and Forestry Resources: A Review and Comparison, Interfaces, 36, 446-457.

Wyatt, R. (2006). Evolutionary Computing for Optimizing A Regions's Distribution of Agricultural Production, Applied GIS, 2, 21.1-21.22.

Wyatt, R. (2008). Optimisation of the Regional Distribution of Agricultural Production - A Genetic Algorithm Prototype. In: Sposito, V., Pelizaro, C., Benke, K., Anwar, M., Rees, D., Elsley, M., O'Leary, G., Wyatt, R. and Cullen, B. (2008). Climate Change Impacts on Agriculture and Forestry Systems in South West Victoria, Australia. Melbourne: Department of Primary Industries, pp. 156171. 


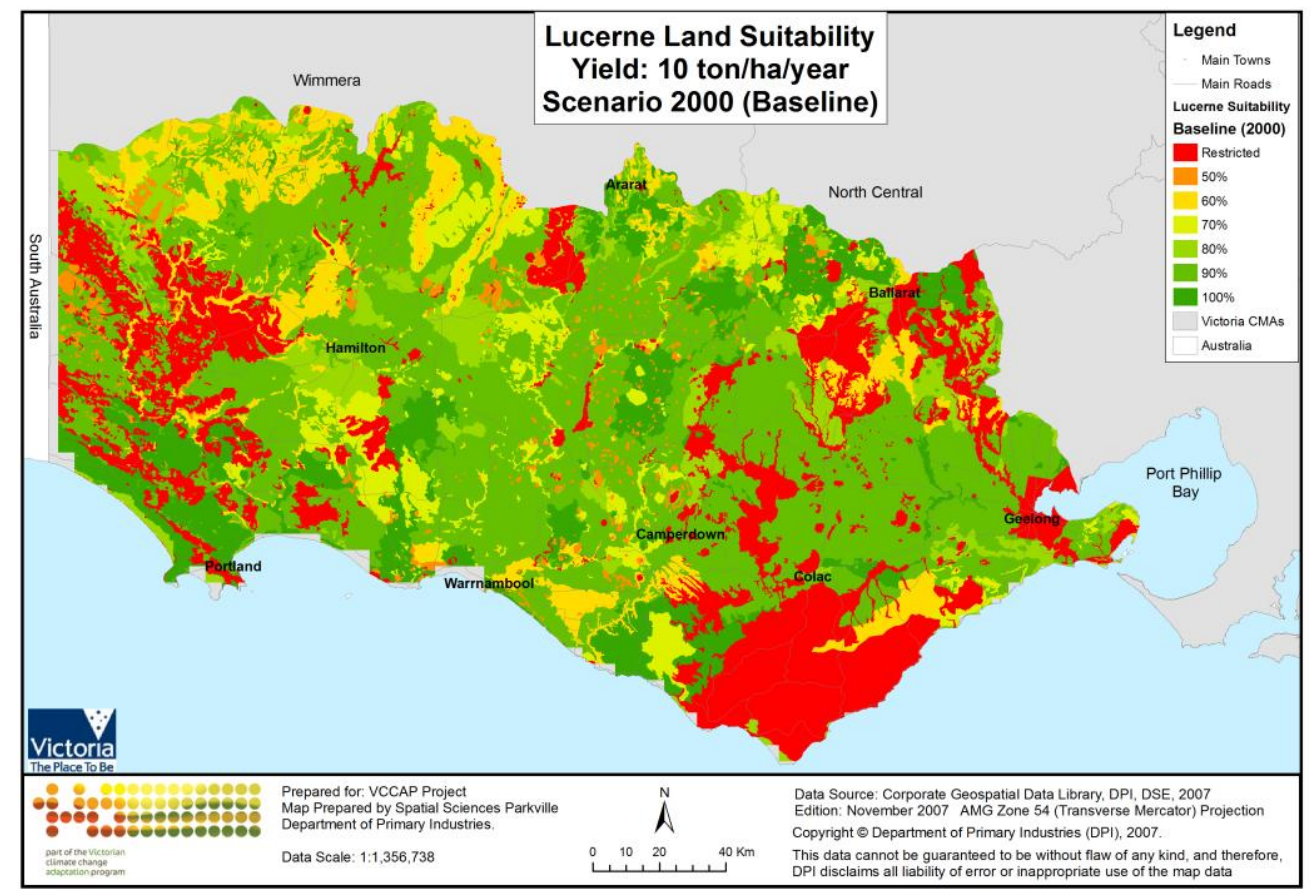

Figure 1. Lucerne land suitability in the year 2000 (Sposito et al. 2008).

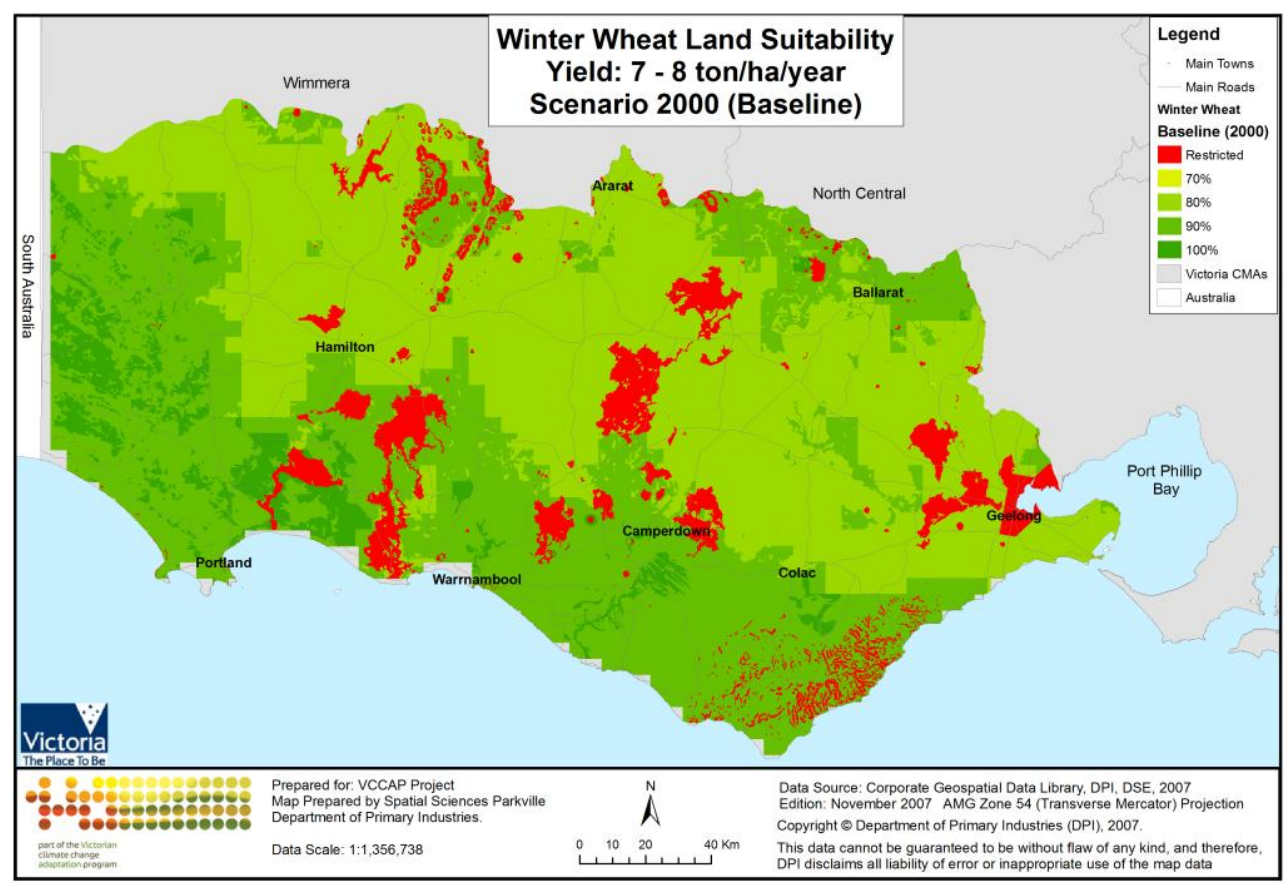

Figure 2. Winter Wheat land suitability in the year 2000 (Sposito et al. 2008). 


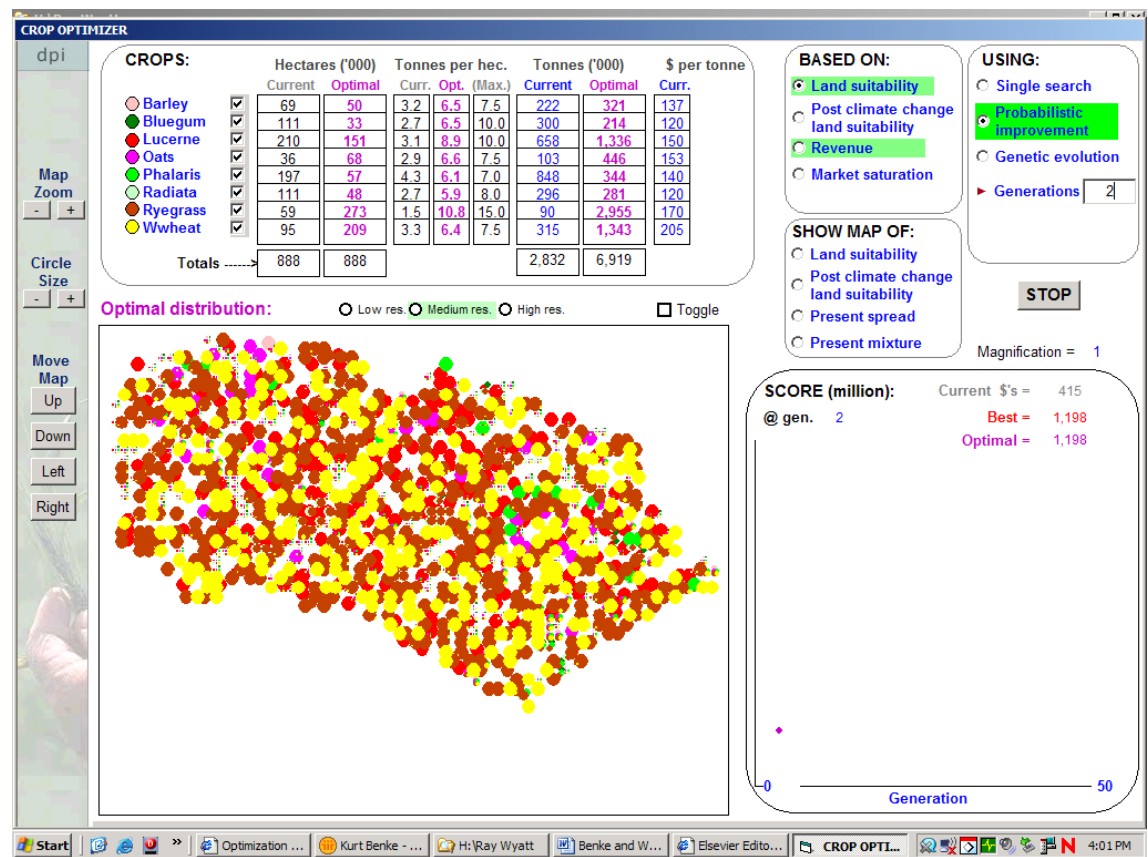

Figure 3. Map of land use optimisation for total revenue (after 2 iterations).

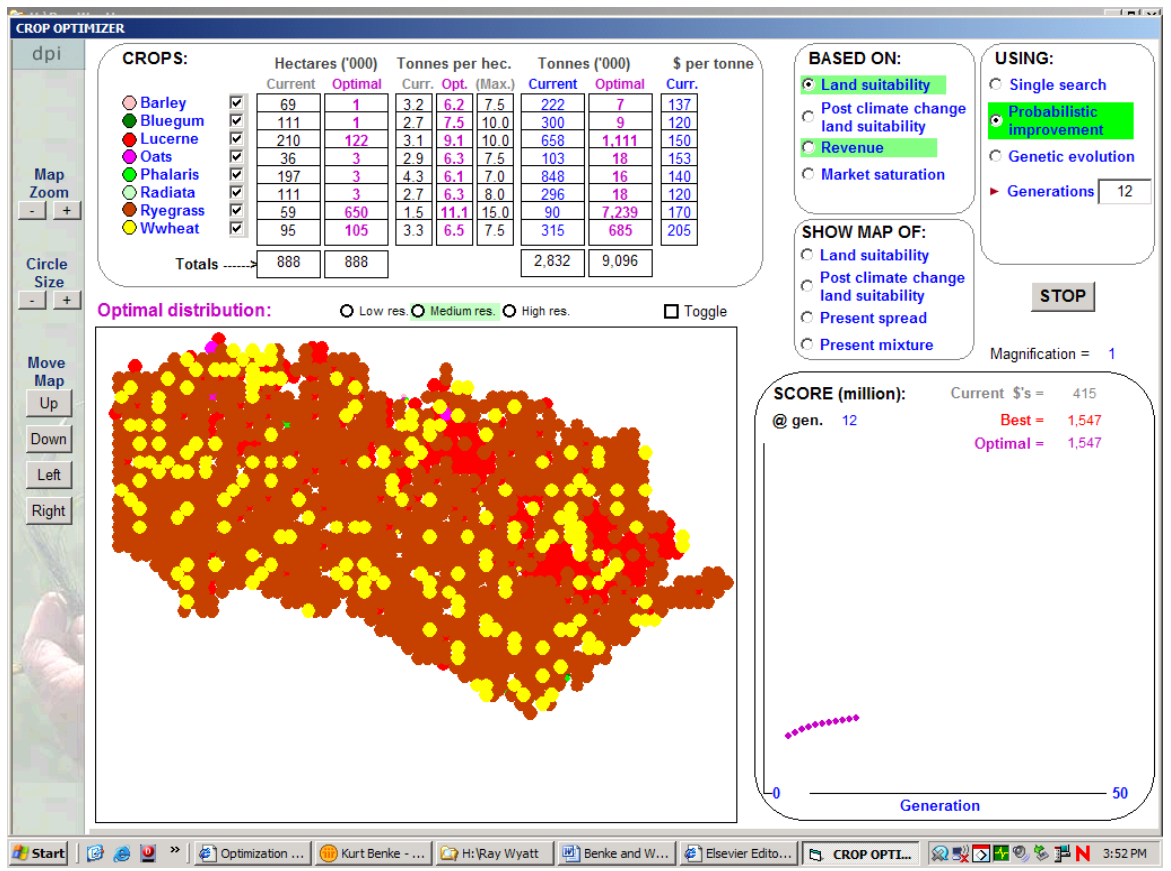

Figure 4. Map of land use optimisation for total revenue (after 12 iterations). 


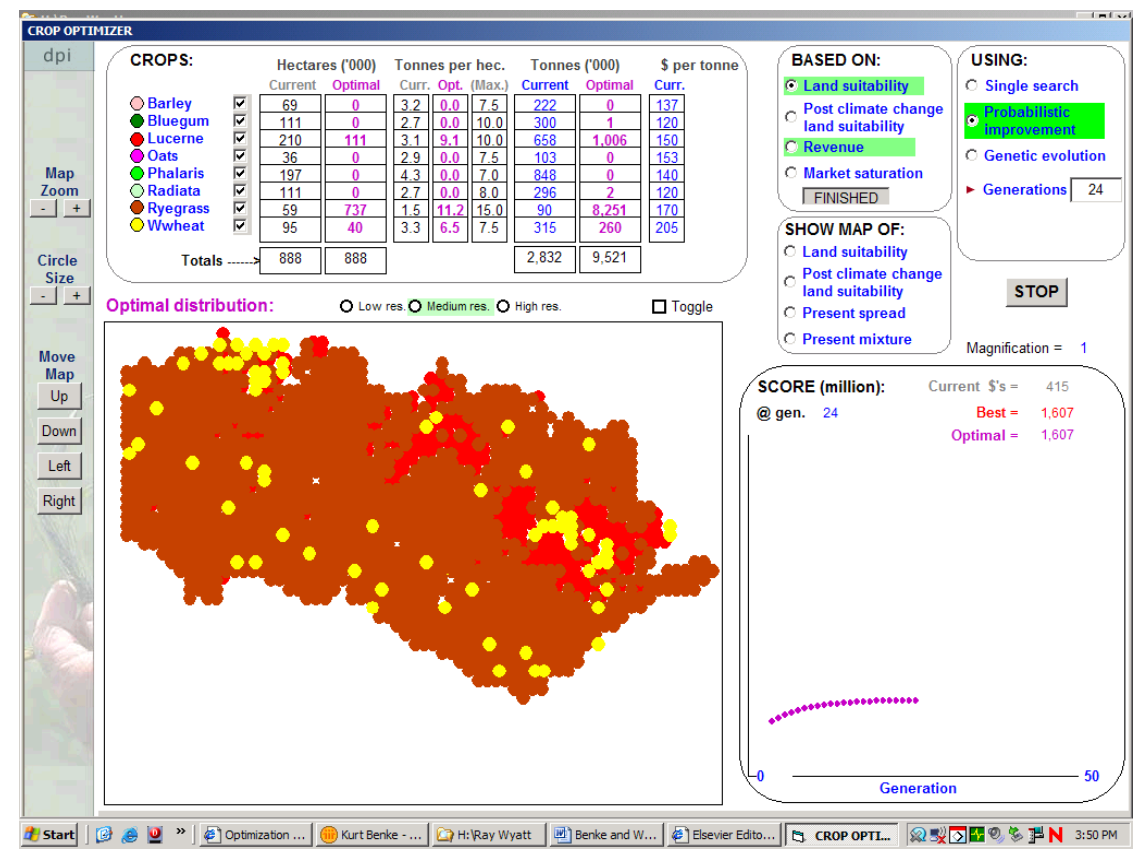

Figure 5. Map of land use optimisation for total revenue (after 24 iterations).

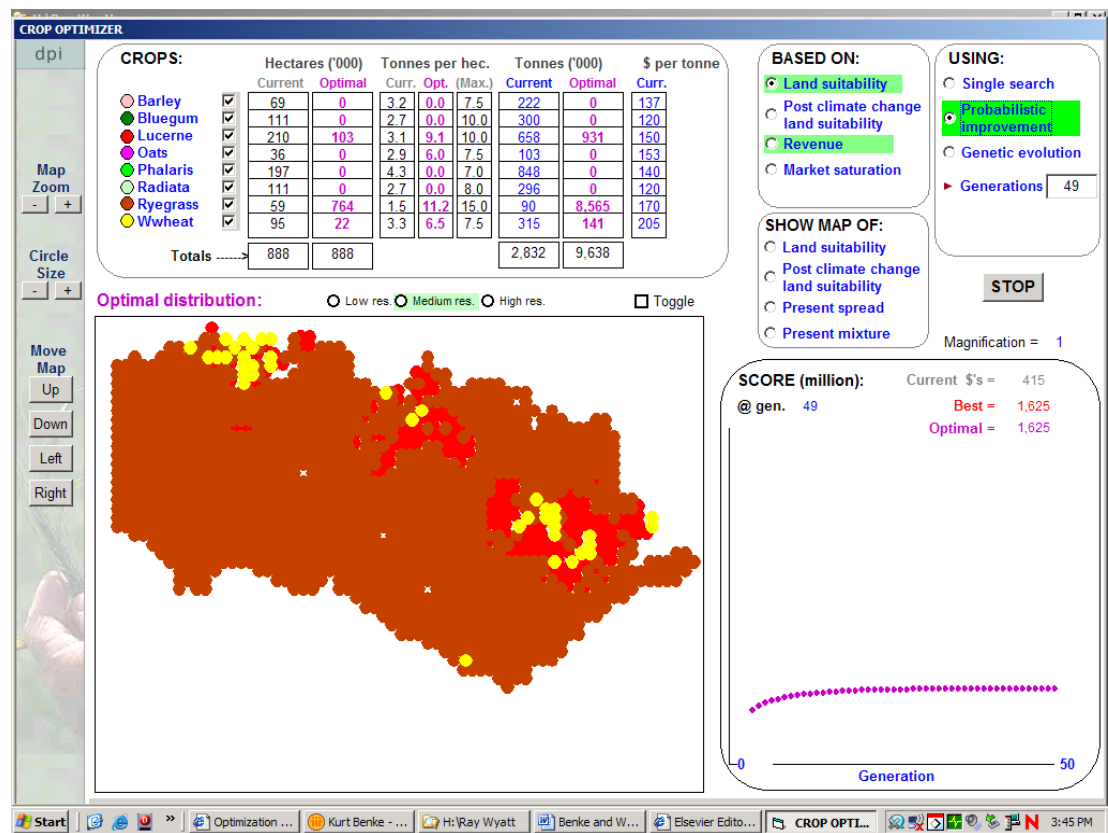

Figure 6. Map of land use optimisation for total revenue (after 49 iterations). 


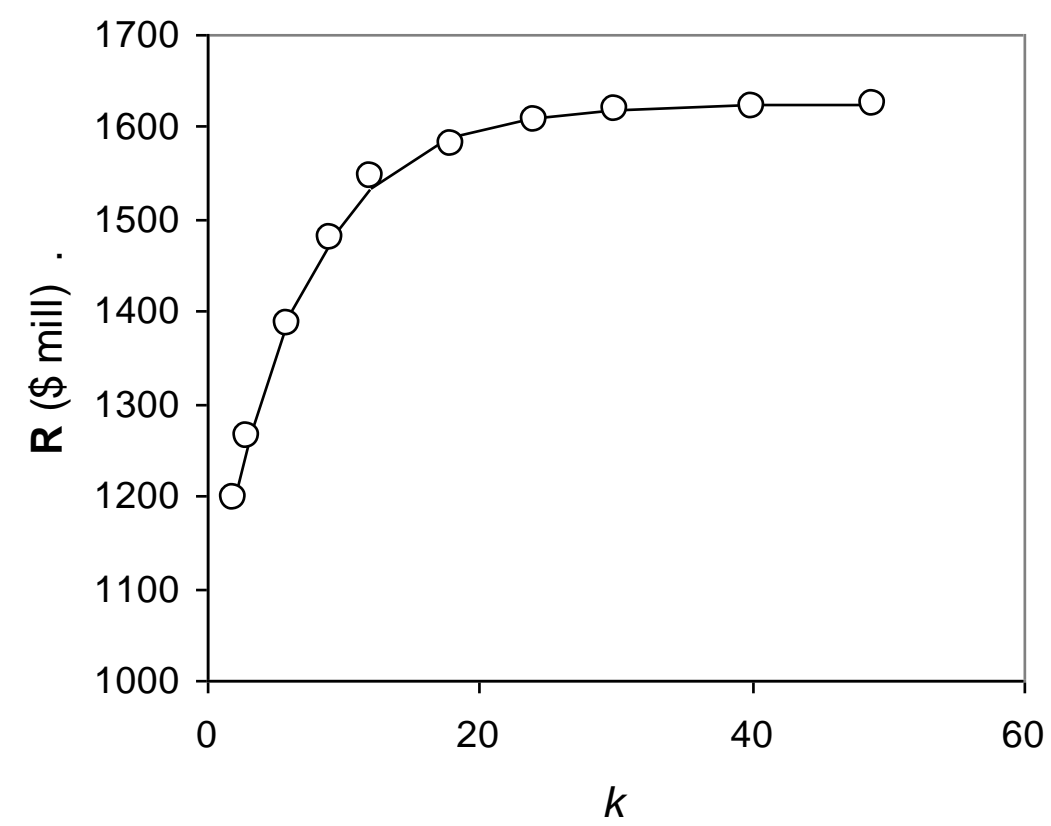

Figure 7. Convergence plot for maximisation of total revenue in the simulation. Open circles represent iterations in the optimisation and solid line represents fit of Eqn (16), where $r^{2}=0.998$.

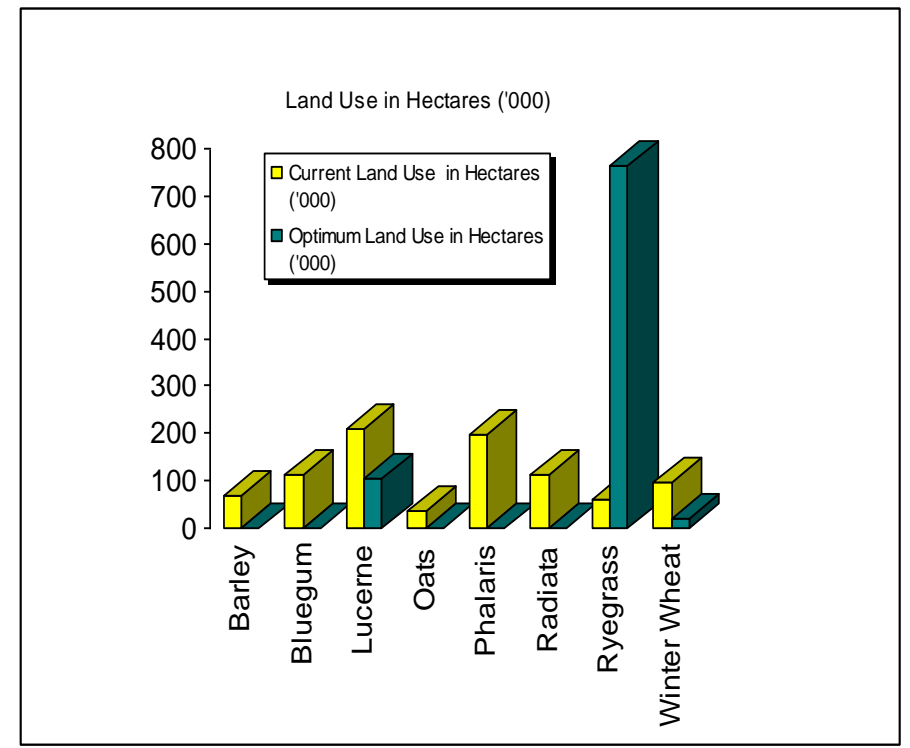

Figure 8. Optimisation of land use produces preference for lucerne, ryegrass and winter wheat, subject to conditions in the current experiment. 


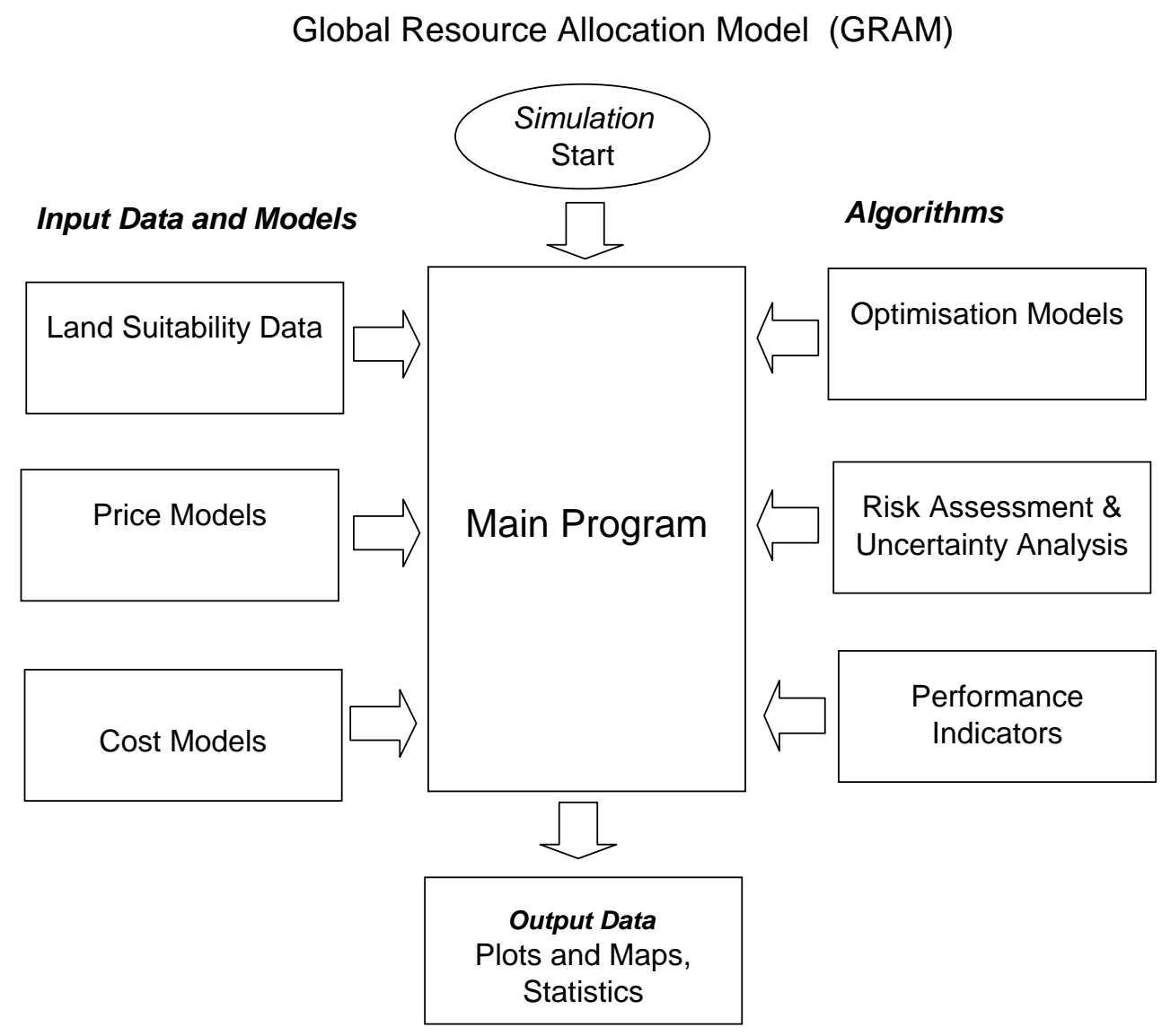

Figure 9. Proposed global resource allocation model (GRAM) would be executed as a probabilistic simulation. The optimised revenue for the region could include confidence intervals and risk assessment data for the solution map. 
Table 1. Total value of agricultural production in the South West Region of Victoria for 2006-7 (Corangamite and Glen Hopkin Region), including pasture and broad-acre crops, horticulture and livestock (Source: ABS, 2008).

\begin{tabular}{|rrrr|}
\hline & Corangamite & Glenelg Hopkin & Gross Value \\
\hline Gross Value $(\$)$ & $944,154,711$ & $1,346,302,299$ & $2,290,457,010$ \\
Local Area(\$) & $891,648,970$ & $1,273,898,709$ & $2,165,547,679$ \\
Total Area (ha) & 805,773 & $2,036,196$ & $2,841,969$ \\
\hline
\end{tabular}




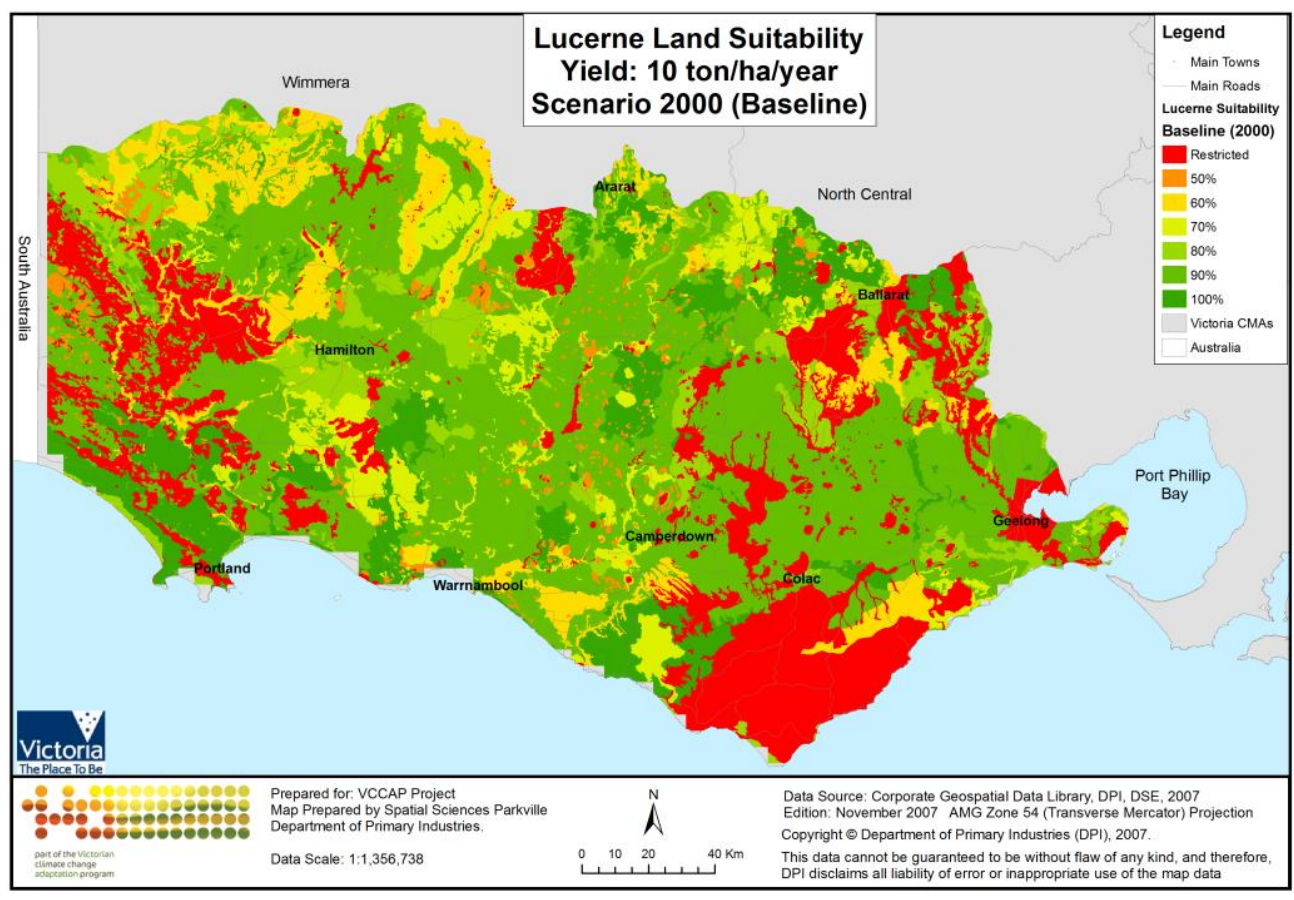

Figure 1. Lucerne land suitability in the year 2000 (Sposito et al. 2008). 


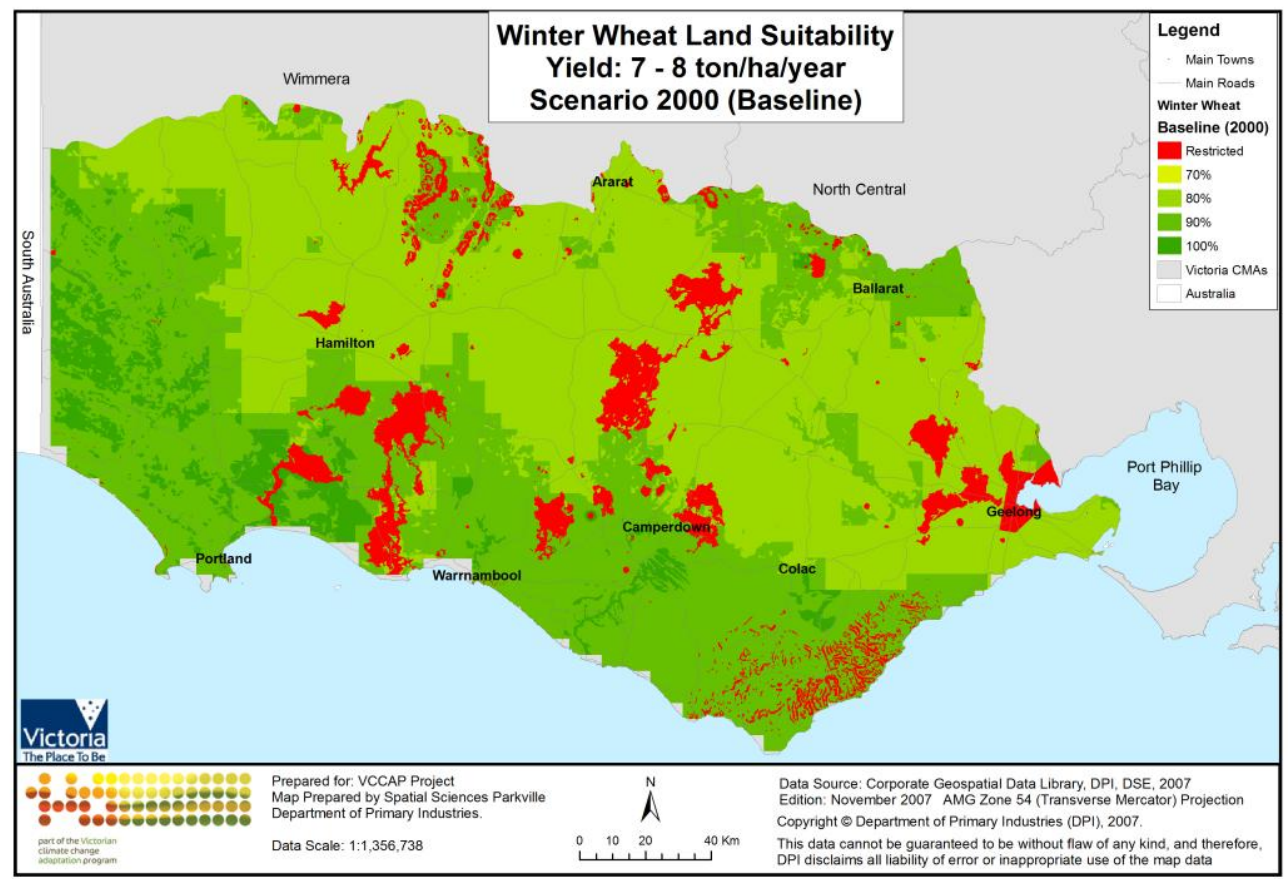

Figure 2. Winter Wheat land suitability in the year 2000 (Sposito et al. 2008). 


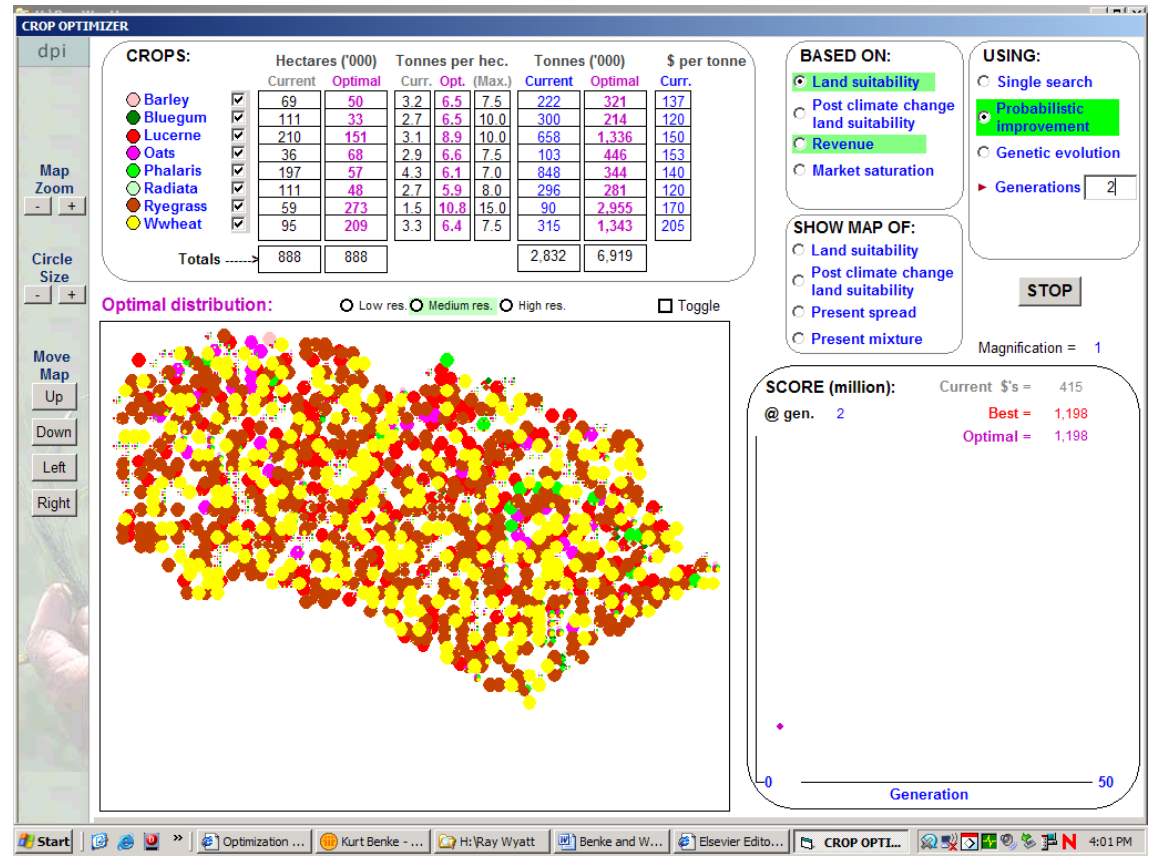

Figure 3. Map of land use optimisation for total revenue (after 2 iterations). 


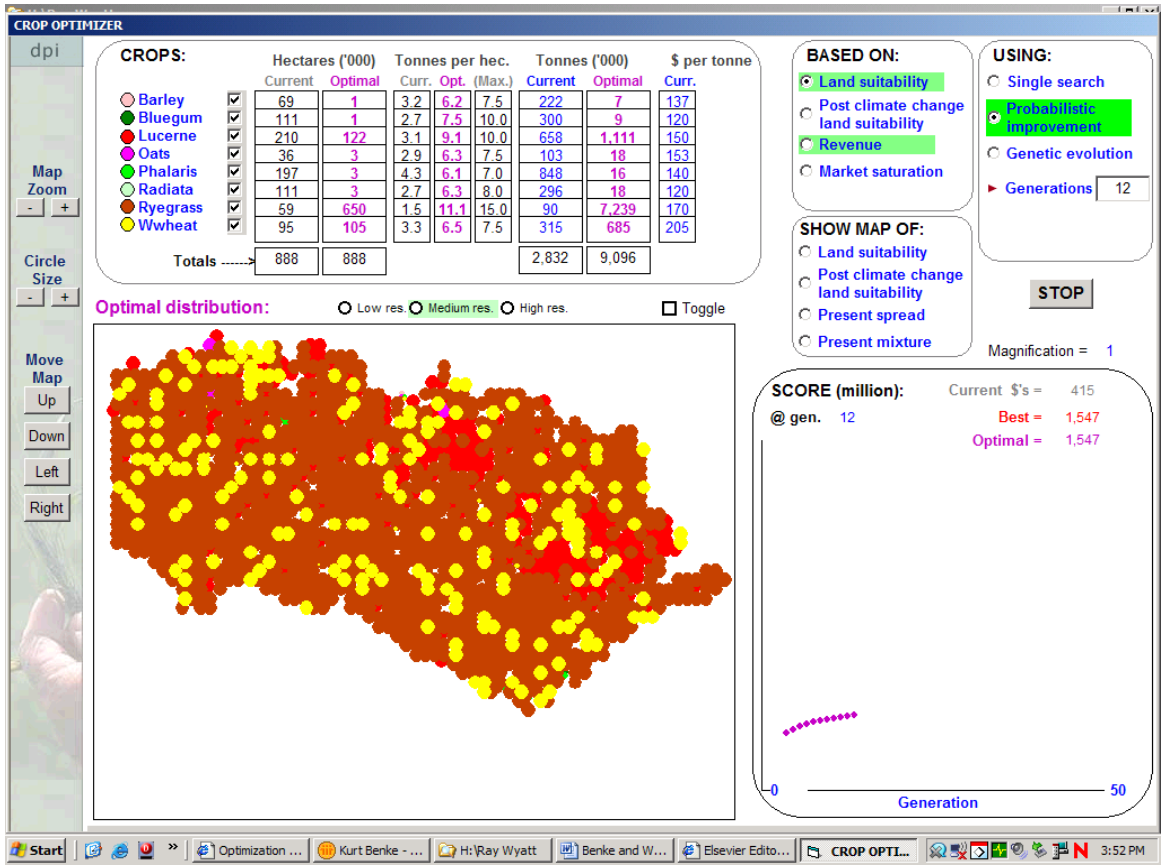

Figure 4. Map of land use optimisation for total revenue (after 12 iterations). 


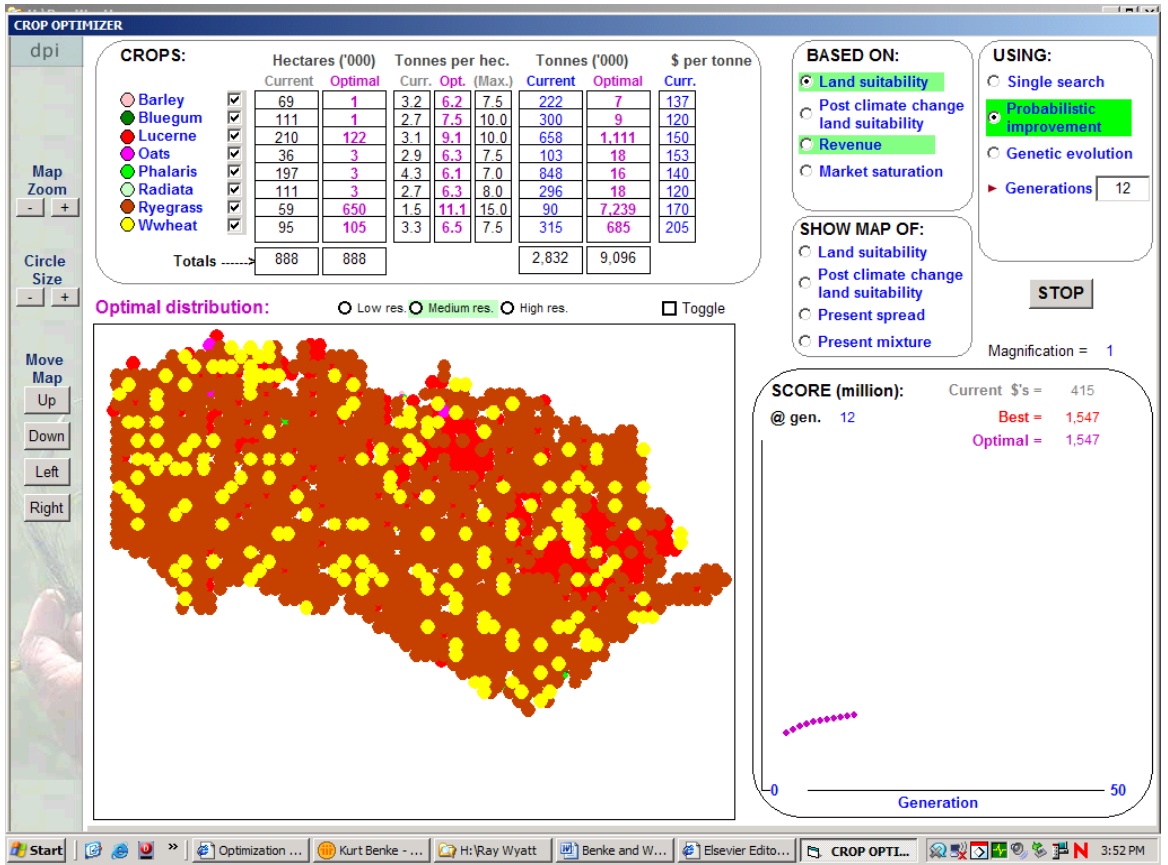

Figure 5. Map of land use optimisation for total revenue (after 12 iterations). 


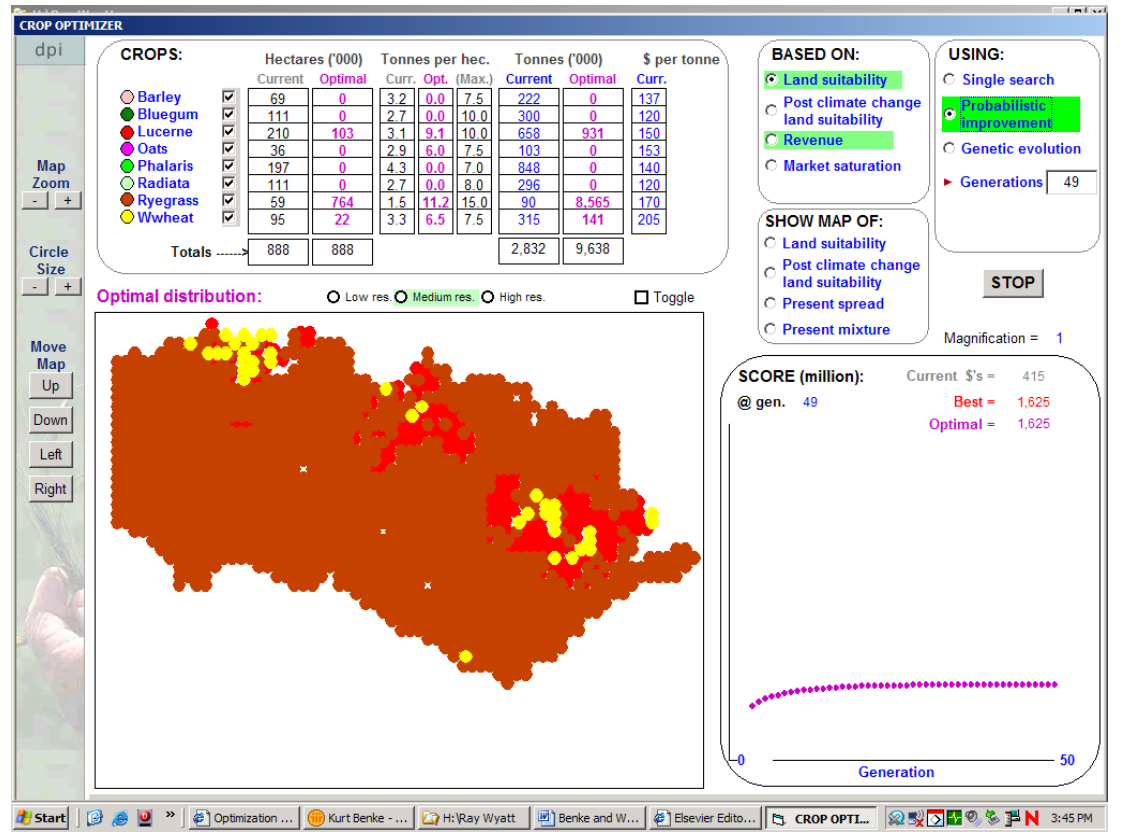

Figure 6. Map of land use optimisation for total revenue (after 49 iterations). 


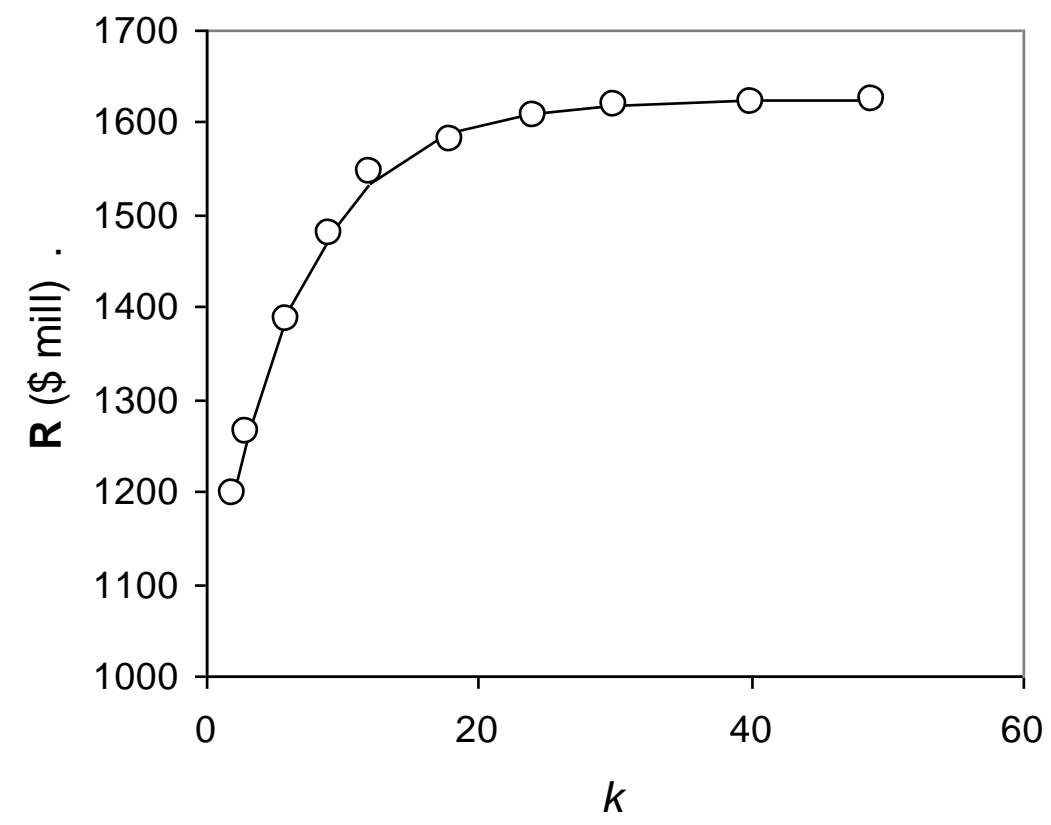

Figure 7. Convergence plot for maximisation of total revenue in the simulation. Open circles represent iterations in the optimisation and solid line represents fit of Eqn (16), where $r^{2}=0.998$. 


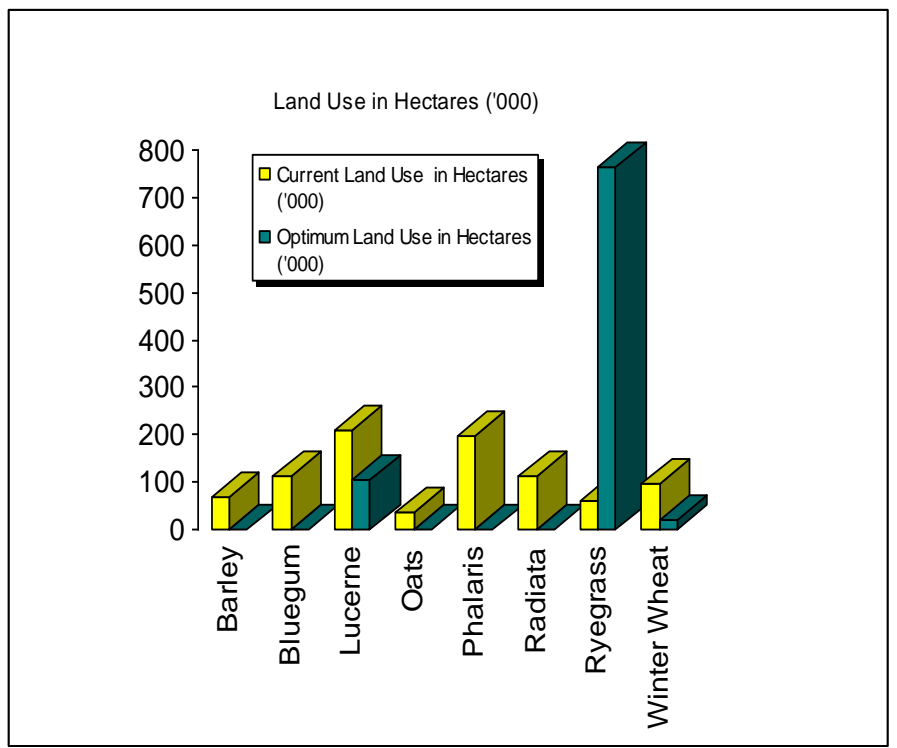

Figure 8. Optimisation of land use produces preference for lucerne, ryegrass and winter wheat, subject to conditions in the current experiment. 


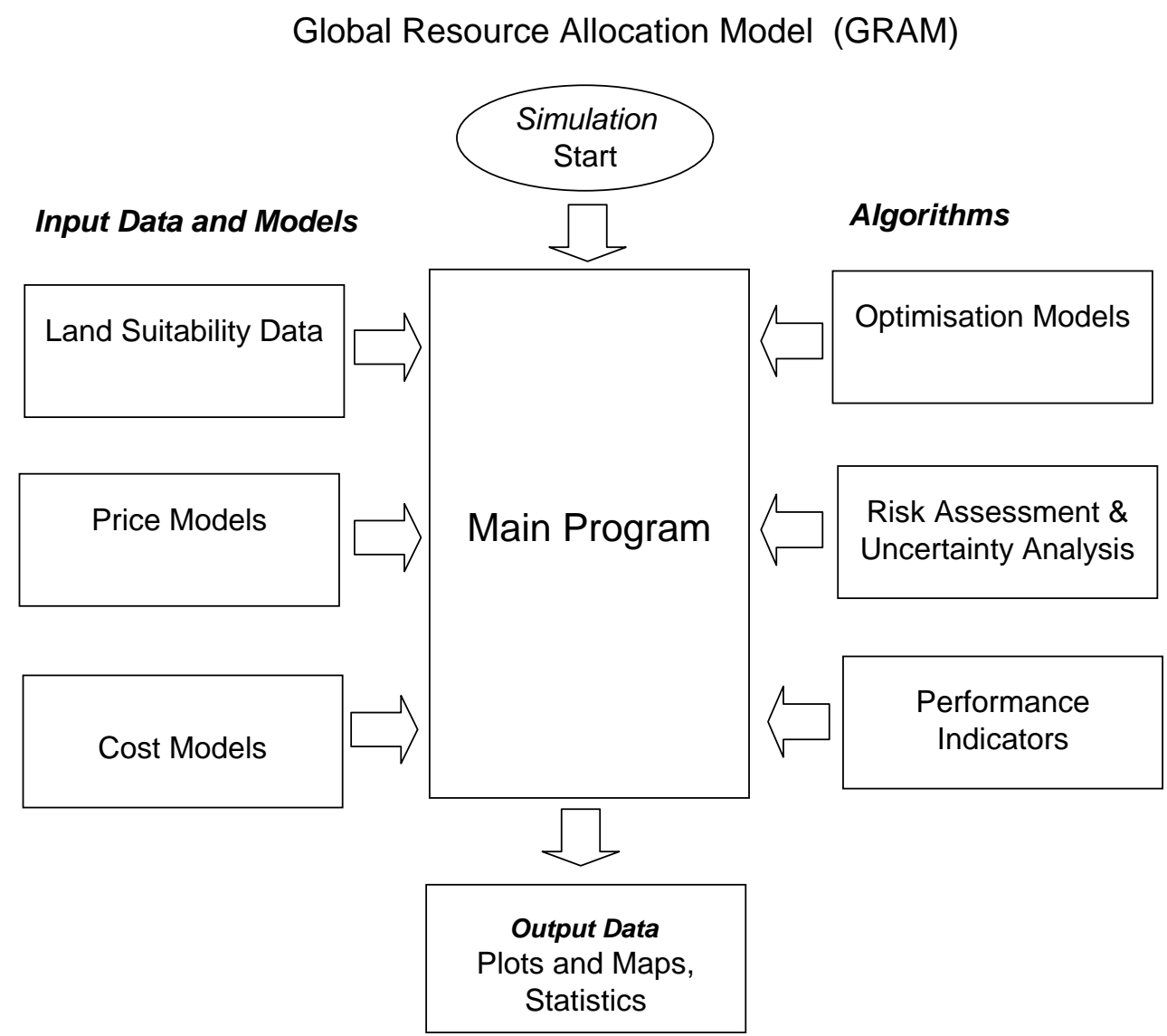

Figure 9. Proposed global resource allocation model (GRAM) would be executed as a probabilistic simulation. The optimised revenue for the region could include confidence intervals and risk assessment data for the solution map. 
Table 1. Total value of agricultural production in the South West Region of Victoria for 2006-7 (Corangamite and Glen Hopkin Region), including pasture and broad-acre crops, horticulture and livestock (Source: ABS, 2008).

\begin{tabular}{|rrrr|}
\hline & Corangamite & Glenelg Hopkin & Gross Value \\
\hline Gross Value $(\$)$ & $944,154,711$ & $1,346,302,299$ & $2,290,457,010$ \\
Local Area(\$) & $891,648,970$ & $1,273,898,709$ & $2,165,547,679$ \\
Total Area (ha) & 805,773 & $2,036,196$ & $2,841,969$ \\
\hline
\end{tabular}




\section{University Library}

\section{- M M N E R VA A gateway to Melbourne's research publications}

Minerva Access is the Institutional Repository of The University of Melbourne

Author/s:

Benke, KK;Benke, LR

Title:

Experiments in Optimal Spatial Segmentation of Local Regions Using Categorical and Quantitative Data

Date:

2013-09-01

Citation:

Benke, K. K. \& Benke, L. R. (2013). Experiments in Optimal Spatial Segmentation of Local Regions Using Categorical and Quantitative Data. APPLIED SPATIAL ANALYSIS AND POLICY, 6 (3), pp.185-208. https://doi.org/10.1007/s12061-012-9078-z.

Persistent Link:

http://hdl.handle.net/11343/283058 